\title{
Understanding consumer adoption of mobile payment in India: Extending Meta-UTAUT model with personal innovativeness, anxiety, trust, and grievance redressal
}

\author{
Pushp Patil \\ School of Management, Swansea University Bay Campus, Fabian Way, Swansea, SA1 8EN, \\ United Kingdom \\ Email:pushpppatil@gmail.com \\ Kuttimani Tamilmani* \\ University of Bradford, Faculty of Business, Law and Social Sciences, Richmond Road, \\ Bradford BD7 1DP, UK, United Kingdom \\ Email: kuttimani.tamilmani@gmail.com \\ Nripendra P. Rana \\ University of Bradford, Faculty of Business, Law and Social Sciences, Richmond Road, \\ Bradford BD7 1DP, UK \\ United Kingdom \\ Email:nrananp@gmail.com \\ Vishnupriya Raghavan \\ Manipal Global Education Services, Bangalore, India \\ Email: vishnupriya.raghavan@gmail.com
}

*Corresponding Author 


\title{
Understanding consumer adoption of mobile payment in India: Extending Meta-UTAUT model with personal innovativeness, anxiety, trust, and grievance redressal
}

\begin{abstract}
Mobile payments are the future as we move towards a cashless society. In some markets, cash is already being replaced by digital transactions, but consumers of many developing countries are slower in transition towards digital payments. This study aims to identify major determinants of consumer mobile payment adoption in India the country with second largest mobile subscribers in the world. Existing mobile payments adoption studies have predominantly utilized Technology Acceptance Model (TAM), which was primarily developed in organisational context and criticized for having deterministic approach without much consideration for users' individual characteristics. Therefore, this study adapted meta-UTAUT model with individual difference variable attitude as core construct and extended the model with consumer related constructs such as personal innovativeness, anxiety, trust, and grievance redressal. Empirical examination of the model among 491 Indian consumers revealed performance expectancy, intention to use, and grievance redressal as significant positive predictor of consumer use behaviour towards mobile payment. Moreover, intention to use was significantly influenced by attitude, social influence, and facilitating conditions. The major contribution of this study includes re-affirming the central role of attitude in consumer adoption studies and examining usage behaviour in contrast to most existing studies, which examine only behavioural intention.
\end{abstract}

Keywords: Mobile payment, Adoption, Use behaviour, Meta-UTAUT, TAM

\section{Introduction}

Mobile devices based payment systems influence lives of people across the globe in ways more than any other innovation in human history to become an integral part of $21^{\text {st }}$ century society. These innovations have gradually shifted daily rigid activities in the physical environment to mobile based virtual environments (Thakur \& Srivastava, 2014). According to the latest World Payments Report (WPR), global non-cash transaction witnessed highest growth during 20162017 to reach 539 billion in volume over the past two decades; emerging Asian markets with $32 \%$ growth rate were the major contributor towards non-cash transaction volumes (Capgemini, 2019). Though, mobile payments have seen limited success in developed countries like the UK (Slade et al., 2015b) due to availability of alternative payment methods. Payment systems such as M-Pesa are readily accepted in developing countries like Kenya, where formal banking penetration is low offering practical solution to previously unbanked customers (Cellan-Jones, 2012). Despite their advantages and increasing prevalence among consumers as an emerging service, mobile payments are still nowhere close to the mainstream (Martin, 2016) and not experienced widespread adoption across the globe as expected (Zhou, 2014a).

India is the second largest mobile market in the world with 616 million subscribers (Gsmaintelligence, 2017), presenting huge opportunity for mobile payment. Although, India's smartphone penetration is 26 percent of the overall population, statistics suggest that only 7.6 percent of India's population use mobile payments for routine transactions(Kats, 2018). India is predominately known as a cash-based economy, heavily dependent on paper based monetary transactions that dominates the commerce activities from daily groceries, restaurant bills, to buying gold or real estate (Chakravorti, 2017; Singh et al., 2020). This status-quo changed, when Government of India (GoI) declared 86 percent of banknotes in circulation invalid on 
November 08, 2016 as part of demonetization drive; emphasising on cashless economy that placed digital payment on the forefront (Singh et al., 2017). Considering digital payment's potential to reach a large proportion of Indian population, GoI undertook various initiatives to develop infrastructure through National Payments corporation of India (NPCI) - an umbrella organisation for all retail payments in India (NPCI, n.d.). However, research regarding mobile payment adoption is still in infancy with majority of the existing studies limited to the location of the researcher focusing on countries like USA and China (e.g., Hongxia et al., 2011; Huang \& Liu, 2012; Wu et al., 2017; Zhou, 2014a, 2014b). In addition, comprehensive literature review on mobile technology adoption found researchers mostly employed Technology Acceptance Model (TAM) (e.g., Sivathanu, 2019; Thakur \& Srivastava, 2014) as theoretical lens that was primarily developed to understand technology users in the organisational context (Chhonker et al., 2017; Chhonker et al., 2018). Therefore, existing research models and findings from other countries are not readily applicable to Indian context as India is a country with multiple cultures and languages with users preferring vernacular languages to English (PWC, 2018). Hence, the purpose of this research is twofold: First to review existing dominant technology adoption models to identify suitable underlying theory and constructs to examine Indian consumers mobile payment use behaviour and second to empirically validate the developed conceptual model by collecting data from the existing mobile payment users in India to uncover their various drivers and inhibitors. The findings emerging from this research could be of significant interest to various stakeholders within mobile payments ecosystem such as payment system providers, marketers, and policymakers.

The remainder of this paper is structured as follows: Section 2 provides review of extant literature pertaining to mobile payment adoption, followed by theoretical background and hypothesis development in Section 3. Next, Section 4 elaborates on the research methodology, after which the results are presented in Section 5. The penultimate Section 6 discuss findings emerging from this research investigation including separate sub-sections on theoretical contributions, implications for practice, limitations and future research directions. Finally, the paper ends with conclusion in Section 7.

\section{Literature Review}

Mobile payment refers to individual's usage of mobile devices including wireless handsets, personal digital assistants, radio frequency devices, and near field communication-based devices for making payments to purchase goods and services (Alkhowaiter, 2020; Chen \& Nath, 2008). This involves integration of payment systems with mobile devices enabling users to initiate, authorize, and complete financial transactions (Srivastava et al., 2010). This study employed keywords such as "Digital Payment" OR "Cashless Payment" OR "Mobile Payment” OR “Adoption” OR “Acceptance” OR “Diffusion” OR “Usage” OR “Intention” OR "Success" OR "Satisfaction" in Scopus database to locate papers relevant to digital payment (Tamilmani et al., 2018a). The keyword search returned 109 initial articles out of which only 47 focused on consumer and were fully downloadable.

\subsection{Emergence of mobile payment research}

Review on extant mobile payments literature found that existing studies mostly focused on developed western countries such as the USA (Crowe et al., 2010; Garrett et al., 2014; Morosan \& DeFranco, 2016), France (De Kerviler et al., 2016; Koenig-Lewis et al., 2015), and UK (Slade et al, 2015a, 2015b). Mallat's (2007) research on Finnish consumer mobile payment adoption through qualitative interviews in late 2002 was one of the earliest studies on mobile payment. The results revealed mobile payments adoption as a dynamic phenomenon 
determined by situational factors such as a lack of other payments methods or urgency. In addition, the study identified several barriers to adoption such as premium pricing, complexity, a lack of critical mass, and perceived risks (Mallat, 2007). Within developing countries context the earliest work appeared in 2008, which includes Eze et al. (2008), conceptual study in the Malaysia and Ho et al.'s (2008), survey based empirical study in China. While the former proposed trust based conceptual model, the later explored the technical feasibility of mobile payment with regards to infrastructure concerning user acceptance. Ho et al. (2008) research data from 250 respondents in Macau made an interesting revelation that people are unlikely to adopt the mobile payments as they stereotype a mobile phone as a communication device and the Internet as a vehicle for e-commerce (Ho et al., 2008). Therefore, understanding various drivers and impediments of mobile payments could ensure better implementation of this technology especially in developing and underdeveloped countries.

\subsection{Construct mapping}

Construct mapping and analysis was done to identify various factors that determine consumer behavioural intention and use behaviour the two most dominant dependent variables (DVs) of mobile payments (Kapoor et al., 2014). The independent variables (IVs) utilised in existing studies are related to various acceptance, adoption and diffusion theories, and models including theory of planned behaviour (TPB), technology acceptance model (TAM), innovation diffusion theory (IDT), unified theory of acceptance and use of technology (UTAUT), and extended UTAUT (UTAUT2). Researchers mostly employed performance outcome variables such as perceived usefulness (PU) (Andreev et al., 2012; Chandrasekhar \& Nandagopal, 2016; Kim et al., 2016) from TAM, performance expectancy (Alshare \& Mousa, 2014; Morosan \& DeFranco, 2016; Slade et al., 2015a, 2015b) from UTAUT, and relative advantage (Lu et al., 2011; Yang, 2012) from IDT as predictors of individual behavioral intention (BI) in using focal technology. Perceived ease of use (PEOU) from TAM, a construct like effort expectancy in the UTAUT was the second most popular antecedent of BI but mostly yielded non-significant results (Koenig-Lewis et al., 2015; Liu, 2012; Phonthanukitithaworn et al., 2015; Shin \& Lee, 2014). Social influence (Alshare \& Mousa, 2014; Musa et al., 2015; Qasim \& Abu-Shanab, 2016; Slade et al., 2015a, 2015b) and facilitating conditions (Morosan \& DeFranco, 2016) remaining two variables from UTAUT were tested relatively on fewer occasions. Researchers have also employed three additional constructs from UTAUT2 such as habit (Morosan \& DeFranco, 2016; Slade et al., 2015a), price value (Oliveira et al., 2016; Slade et al., 2015a), and hedonic motivation (Koenig-Lewis et al., 2015; Morosan \& DeFranco, 2016) but less frequently. Besides the variables from popular theories, researchers have employed serval variables such as information security (Alshare \& Mousa, 2014; Di Pietro et al., 2015; Oliveira et al., 2016; Zhong et al., 2013), privacy concerns (Morosan \& DeFranco, 2016), knowledge (Koenig-Lewis et al., 2015), positive emotions (Wu et al., 2016), self-efficacy (Makki et al., 2016), subjective norms (Liébana-Cabanillas et al., 2014a), network externalities (Qasim \& Abu-Shanab, 2016), adoption readiness (Thakur \& Srivastava, 2014), trust, risk, and innovativeness (Phonthanukitithaworn et al., 2015; Qasim \& Abu-Shanab, 2016; Slade et al., 2015a),

Only four studies (Hongxia et al., 2011; Koenig-Lewis et al., 2015; Sivathanu, 2019; Tian \& Dong, 2013) examined adoption or use behavior as outcome variable. This indicates mobile payment is still an emerging topic and researchers are using consumer intention as proxy for their actual behavior. These four studies examined the role of a limited number of independent variables (IVs) including risk (Hongxia et al., 2011), BI (Hongxia et al., 2011; Koenig-Lewis et al., 2015; Sivathanu, 2019; Tian \& Dong, 2013), PU (Tian \& Dong, 2013), fee/cost (Tian \& Dong, 2013), knowledge (Koenig-Lewis et al., 2015) and innovation resistance (Sivathanu, 
2019) and found them to significantly influence consumer mobile payment adoption or usage behavior. Mobile payments research in Indian context first got published in the year 2014 (Thakur \& Srivastava, 2014) followed by the second one in 2016 (Chandrasekhar \& Nandagopal, 2016). In addition, two more studies got published more recently in 2018 (Shankar \& Datta, 2018) and 2019 (Sivathanu, 2019) taking the total count to four. Three studies examined only consumer intention to adopt/use digital/mobile payment system without measuring actual adoption/use. Only Sivathanu (2019) examined both intention and actual acceptance to provide a more holistic understanding. However, data for this study was collected just after demonetization announcement so consumer perception may have been influenced by socio-political conditions of that time, which needs further validation. In addition, data for this study is collected from a limited geographical area in India. Given the extent of diversity (particularly in terms of socio-economic conditions) in different Indian states and regions, results from this study may not be generalised fully. There are also some issues with theoretical choices. Considering these issues, it would be useful to conduct further research on consumer adoption of digital/mobile payment in an Indian context.

\section{Theoretical background and hypotheses development}

Researchers have employed numerous information systems/information technology (IS/IT) theories to understand individual acceptance and use of information systems. Several literature reviews on mobile technologies have repeatedly found TAM and UTAUT as two topmost theoretical lens to examine individual technology adoption (e.g., Chhonker et al., 2018; Slade et al., 2015b). Therefore, it is useful to understand limitations of such models before selecting theoretical lens for the current study.

\subsection{Technology acceptance model (TAM)}

TAM emerged as the most popular theory in the review of mobile payments studies with researchers adopting, adapting, and extending the model across various use contexts. For instance, while Augsburg and Hedman (2014) utilised TAM alongside innovation diffusion theory (IDT) to explore adoption of mobile payments and value added services (VAS). Zhanga et al. (2011) employed TAM standalone to explore factors affecting the adoption of mobile payment across various cultural settings. These findings are consistent with Slade et al.'s (2015b) literature review on consumer mobile payment adoption and Chhonker et al.'s (2018) review on mobile commerce that found researches to employ Davis' (1989) TAM as preferred theoretical lens in around 50\% of studies. Despite emerging as the most popular model to measure consumer mobile payment adoption, TAM is criticised for providing very generic information on individuals' opinions and acceptance of such novel technologies. Because, TAM was originally developed in the organisational context without enough consideration for users' individual characteristics having deterministic approach assuming technology usage is volitional without constraints (Agarwal \& Prasad, 1999; McMaster \& Wastell, 2005).

\subsection{UTAUT Theories}

Many competing theories emerged towards the end of $20^{\text {th }}$ century to address the limitations of TAM, such as diffusion of innovation (DoI) theory, IDT, and model of personal computer utilisation to explain individual adoption of IS/IT. This multitude of contexts and theories presented new challenge of plurality to IS researchers (Tamilmani et al., 2017, 2018b). Venkatesh et al. (2003) developed comprehensive UTAUT based on thorough review of eight dominant technology adoption models (see Venkatesh et al., 2003) to overcome 
limitations of existing theories. UTAUT postulates performance expectancy, effort expectancy, and social influence as direct determinants of behavioural intention that together with facilitating conditions affects use behaviour. UTAUT emerged as the second most popular theoretical lens in understanding consumer mobile payment adoption (Patil et al., 2017). For instance, Slade et al. (2015a) utilised UTAUT to examine consumer adoption of proximity mobile payments in the UK. However, like other popular IS adoption models, UTAUT was also originally developed within an organisational context to explain employee technology acceptance. Therefore, Venkatesh et al. (2012) proposed an extended version of UTAUT tailoring the model to consumer technology acceptance context, which is popularly known as UTAUT2.

\subsection{Meta-UTAUT model}

Despite the comprehensiveness and popularity, UTAUT based theories have numerous inherent limitations (Tamilmani et al., 2020). Dwivedi et al. (2019) state prior research have acknowledged limitations of UTAUT both explicitly and implicitly during their empirical investigations. They re-examined UTAUT model through a combination of meta-analysis and structural equation modelling (MASEM) technique to address some of those limitations. Henceforth, this study will refer to the re-examined model as meta-UTAUT. The reexamination found that the researchers sparingly applied the UTAUT model on its entirety with scare inclusion of moderator relationships. The most important revelation was UTAUT model lacked attributes on 'individuals' who engage with technology that could be influential in explaining their dispositions towards use of underlying technology. Dwivedi et al.'s (2019) revised model included attitude as a mediating construct, and they tested the model using MASEM technique with data collected from 162 prior UTAUT based studies cumulatively comprising of 1,600 observations. The results revealed attitude to partially mediate the effects of all four UTAUT exogenous variables to behavioural intention. The emergent model with the inclusion of attitude increased the exploratory power on behavioural intention significantly to $45 \%$, which was just 38\% without attitude (Dwivedi et al., 2019). The preceding discussion underscores the significant role of attitude in predicting individual technology acceptance.

Moreover, attitude plays more prominent role on individual intentions towards performing underlying behaviour especially during early stages of technology adoption. Therefore, metaUTAUT model would be most appropriate to understand Indian consumer adoption of mobile payments. Because, on the one hand it represents the unified model with attitude as a new mediating variable; on the other hand, it is a more comprehensive and less complicated model than UTAUT. Further, it is also important to validate this theory as it has not been tested empirically for individual acceptance and use of any IS/IT in general and particularly mobile payment. Though meta-UTAUT has overcome several limitations of the UTAUT model, it still requires some context specific external constructs that can more appropriately capture all possible aspects of mobile payment. And, it is also essential to strike a balance between parsimony and comprehensiveness while proposing a research model (Whetten, 1989). Realising this, the current study has included some additional constructs such as anxiety, trust, personal innovativeness, and grievance along the key constructs of the meta-UTAUT model. Figure 1 depicts the proposed research model with appropriate hypotheses. The conceptual model comprises of 12 hypotheses in total, six of these hypotheses (H1, H3, H4, H5, H11, and H12) are existing relationships in the meta-UTAUT model. The remaining six relationships are new with hypotheses $\mathrm{H} 2$ and $\mathrm{H} 6$ among existing meta-UTUAT constructs termed as new internal mechanism. Meanwhile, hypotheses H7, H8, H9, and $\mathrm{H} 10$ having association between new external variables and meta-UTAUT endogenous variables termed as new endogenous 
mechanism (Dwivedi et al., 2020). The next section on hypotheses development establish the associations amongst all the variables in the proposed model and their context in examining Indian consumer mobile payment adoption.

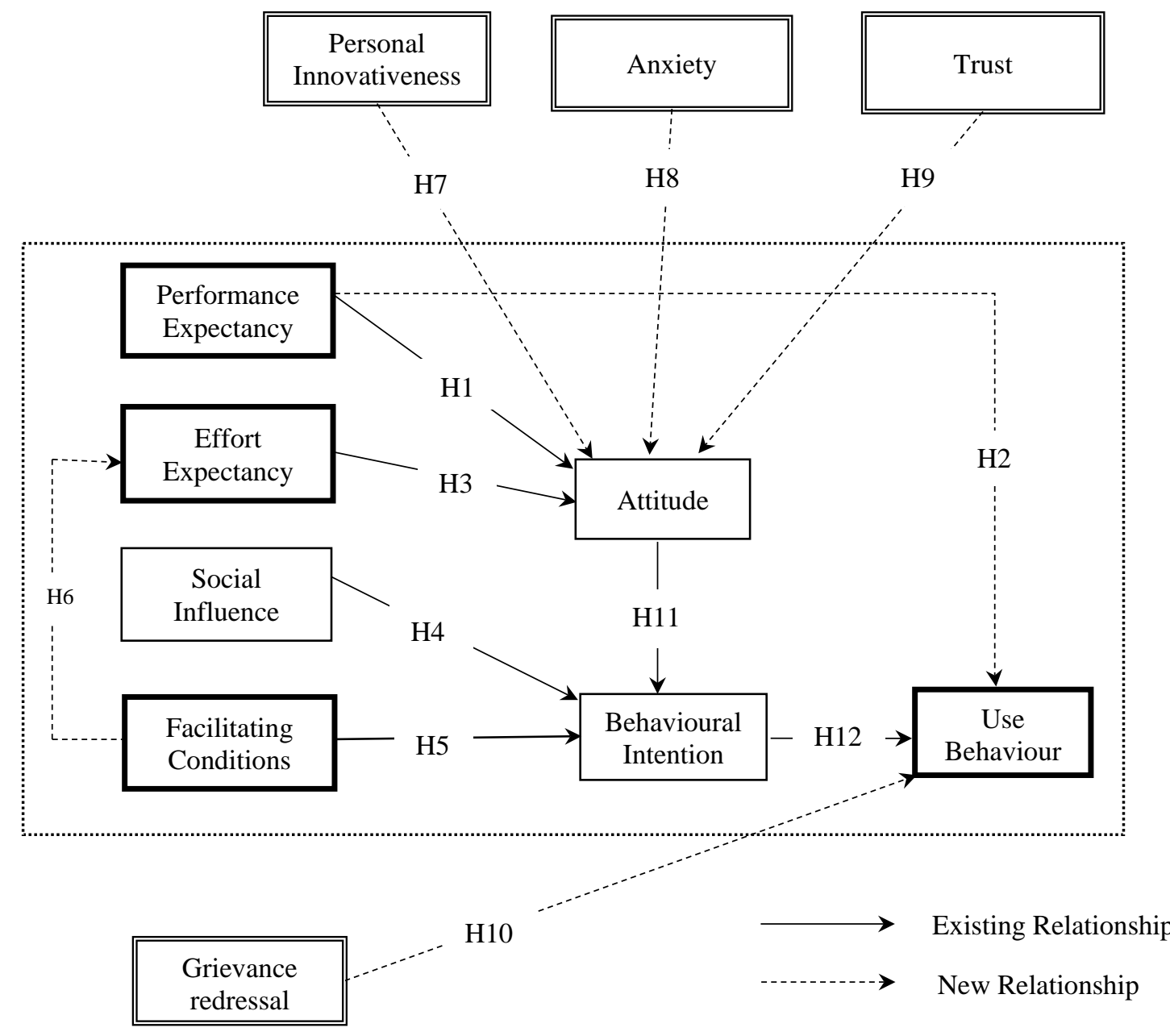

Meta-UTAUT $\square$ New Internal mechanism $\square$ New Endogenous mechanism

Figure. 1. Proposed research model (Source: Adapted from Dwivedi et al., 2019)

\subsection{Hypotheses development}

\subsubsection{Performance expectancy}

Performance expectancy (PE) is defined as the level to which an information system or technology will offer benefits to consumers in performing specific activities (Alalwan et al., 2017; Baabdullah et al., 2019; Venkatesh et al., 2012). The five different constructs and corresponding theories that pertain to unification of performance expectancy construct are as follows: perceived usefulness (TAM/TAM2), job fit (MPCU), extrinsic motivation (MM), relative advantage (IDT), and outcome expectations (SCT) (Venkatesh et al., 2003). Prior researchers found PE as the strongest predictor of consumers' belief and intentions toward adopting a technology (Venkatesh et al., 2012). Numerous studies (e.g., Alaeddin et al., 2018; 
Bailey et al., 2017; Tian \& Dong, 2013; Wulandari, 2017) across the world within mobile payment environment have reported the significant relationship of PE or its surrogate construct(s) on consumer attitude. In the Eastern countries, researchers such as Aslam et al. (2017) and Tian and Dong (2013) found the positive and significant impact of perceived usefulness on consumer attitude toward the usage of mobile payment services in Pakistan and China respectively. Meanwhile, Wulandari (2017) found the impact of PU on attitude as significant while analysing the acceptance of cashless payment in tourism in Indonesia. With regards to developed Western countries Bailey et al. (2017) and Schierz et al. (2010) established a positive and significant relationship between perceived usefulness and consumer attitude towards mobile payment adoption in the USA and Germany respectively. Based on existing findings and considering perceived usefulness as one of the strongest surrogates of performance expectancy, this research also proposes the following hypothesis:

H1. Performance expectancy will positively affect consumer attitude towards using the mobile payment systems.

Perceived usefulness of mobile payment systems or benefits offered by paying through the mobile systems can also help the adopters or the existing consumers toward improved use of the system. Most of the studies analysing the adoption of mobile payment systems have not discussed the consumer use behaviour of such systems. None of the above studies that talked about the influence of perceived usefulness on attitude has considered use behaviour as a construct in their proposed research model. There are two possible reasons for it. First, as research on mobile payment adoption is still in its early stage, researchers did not collect data from the adopters of such systems and hence there is no further explanation of use behaviour in the model. Second, the measures of use behaviour are quite diverse and used as per the specific context of the research. Most of the time, they are not measured on the Likert scale like other constructs in the model. Hence, researchers do not tend to use this construct and measure them like other constructs. To overcome such limitations, the current research has not only collected several relevant measures but also used them in the proposed research model. In this way, the proposed research model has used the entire meta-UTAUT model and justified its use by collecting data from the existing consumers of the mobile payment systems. This way, it could be argued that the usefulness of the mobile payment system not only improves consumers' positive attitude toward using it but also enhances the actual use of such a system. Deriving from the above arguments, the following hypothesis can be formulated:

H2. Performance expectancy will positively affect consumer use behaviour of the mobile payment system.

\subsubsection{Effort expectancy}

Effort expectancy (EE) is defined as the degree of ease linked with the use of technology (Venkatesh et al., 2012). Three constructs that pertain to unification of effort expectancy are as follows: perceived ease of use (TAM/TAM2), Complexity (MPCU), and ease of use (IDT) (Venkatesh et al., 2003). Technology adoption researchers have reported mixed outcome i.e. both significant as well as non-significant impact of EE or its surrogate constructs both on attitude and behavioural intentions. To date, a handful of studies (e.g., Bailey et al., 2017; Schierz et al., 2010; Wulandari, 2017) have explored the impact of EE or similar variables on consumer attitude to use mobile payment systems and found them significant, while some other studies (e.g., Aslam et al., 2017) have found this relationship as non-significant. For the nonsignificant impact of PEOU on attitude, consumers consider ease of using the mobile payment 
as unimportant and hence this is no longer a variable that plays a significant role in the decisionmaking process for adopting the use of mobile payment (Aslam et al., 2017).

Researchers explored various categories of mobile payment systems and have found this relationship as significant for some categories whereas the same relationship was found nonsignificant for some other type(s) of mobile payment systems. For instance, De Luna et al. (2019) studied consumer acceptance of three types of mobile payments systems such as Short Message Service (SMS), Near Field Communication (NFC), and Quick Response (QR) found the impact of PEOU on attitude to be significant only for SMS based transactions and nonsignificant for the other two payment systems. The plausible explanation for SMS based payments systems is that they are still in nascent stages in comparison to NFC and QR codebased systems with higher rate of adoption where users find less difficulty in handling the tool. Despite large number of the population having mobile phones, mobile payment system is still not mature in India with only a handful of them using them for payment. This research argues that the effect of EE on consumer attitude would be significant in such context. Based on the above discussion, the following hypothesis could be formulated:

H3. Effort expectancy will positively and significantly influence the consumer attitude to use mobile payment systems.

\subsubsection{Social influence}

Social influence is defined as the degree to which the consumer perceives that important others (e.g. family, friends, colleagues etc.) in their life believe that they should use a specific technology (Baishya \& Samalia, 2020; Venkatesh et al., 2012). Social influence is unification of three similar constructs such as subjective norm (in TRA, TAM2, TPB, and DTPB), social factors (MPCU), and image (IDT). This attribute emerged as significant predictor of behavioural intentions in both UTAUT and UTAUT2 under the influence of age, gender, and experience as moderating variable. However, using meta-UTAUT model, Dwivedi et al. (2019) established the impact of social influence on behavioural intentions without any moderating variable. Numerous studies within mobile payment environment have reaffirmed the significant impact of social influence on behavioural intentions across the globe including China (Guo \& Lu, 2017), Qatar (Musa et al., 2015), and Portugal (Oliveira et al., 2016) to name a few. Analysing the consumer adoption intentions of the remote mobile payment (RMP) in the UK, Slade et al. (2015b) found social influence as the strongest predictor of non-adopters' behavioural intention to use RMP. Therefore, based on the above discussion, the following hypothesis can be proposed:

H4. Social influence will positively and significantly influence the consumer intention to adopt mobile payment systems.

\subsubsection{Facilitating conditions}

Facilitating conditions refers to consumers' belief of the resources and support available to them to perform a behaviour (Dwivedi et al., 2007; Venkatesh et al., 2012). This indicates if the operational infrastructure exists and facilitates to use of mobile payment, the behavioural intention to adopt mobile payment will increase (Oliveira et al., 2016). A few studies (e.g., Morosan \& DeFranco, 2016; Sivathanu, 2019) on mobile payment adoption have endorsed the significant impact of facilitating conditions on behavioural intention, whereas some others (e.g., Oliveira et al., 2016) found them as non-significant. For example, based on the data from 
a sample of 794 hotel consumers selected from the US general population, Morosan and DeFranco (2016), revisited the UTAUT2 to build a rigorous model that explains intention to use near field communication-mobile payments in hotels and found a significant influence of facilitating conditions on users' behavioural intentions. Investigating the actual use of digital payment systems by the consumers during the period of demonetization from $8^{\text {th }}$ November 2016 until 30 ${ }^{\text {th }}$ December 2016 in India, Sivathanu (2019) tested whether BI to use digital payment systems is explained by FC and the findings were supported by the data gathered for this research.

However, while understanding the determinants of customer mobile payment adoption in Portugal, Oliveira et al. (2016) found the relationship between facilitating conditions and behavioural intentions as non-significant. The possible reason for this non-significant relationship is the nature of the respondents (i.e. students and alumni from the University of Portugal) from whom the data were gathered. As they do not need any potential resources and support to use mobile payment, it is not surprising that this relationship was non-significant. The current study intend to gather data from diverse backgrounds, educational status and financial status. Therefore, the following hypothesis could be formulated:

H5. Facilitating conditions will positively and significantly influence the consumer intention to adopt mobile payment systems.

In addition to behavioural intention, researchers have also reported significant influence of facilitating conditions on effort expectancy or its surrogate constructs (e.g. perceived ease of use) (e.g., Stefi, 2015; Venkatesh \& Bala, 2008). Venkatesh and Bala (2008), in their TAM3 model, proposed perceived behavioural control as antecedent of perceived ease of use on basis of anchoring and adjustment framework in human decision-making. Their results over four time periods amongst four different organisational users of technology found perceived behavioural control as significant predictor of perceived ease of use at all points of measurement. Since then researchers have examined the significant role of perceived behavioural control/facilitating conditions on perceived ease of use/effort expectancy to evaluate individual technology acceptance across range of technological and cultural context. For example, Stefi (2015) examined the developers' adoption to use existing software components and found that facilitating conditions to lower developers' effort when integrating existing components. The positive impact of facilitating conditions on effort expectancy in the context of consumer mobile payment adoption indicates that the availability of operational infrastructure (i.e. training programs, organisational and technological infrastructure and making relevant resources available to facilitate the use of transactions through mobile payment) would help consumers to easily understand the mobile operations to get their work done. Realising the above discussion, the following hypothesis can be formulated:

H6. Facilitating conditions will positively and significantly influence effort expectancy.

\subsubsection{Personal innovativeness}

The term 'innovativeness' refers to an individual's desire to seek out something new and different (Hirschman, 1980). Therefore, the degree to which an individual is open to experience or try something new is an expression of their innovativeness or novelty-seeking tendencies. Although innovativeness has not been part of any prominent theoretical models of technology acceptance, it has acquire support as a crucial predictor of new product or innovation adoption across other disciplines (Agarwal \& Prasad, 1998; Cowart et al., 2008; Karjaluoto et al., 2019; 
Slade et al., 2014). Agarwal and Prasad (1998, p. 206) proposed innovativeness term specific to information technology domain as personal innovativeness of information technology (PIIT) and defined PIIT, as "the willingness of an individual to try out any new information technology”. Furthermore, Agarwal and Prasad (1998) developed and validated the measures for personal innovativeness specific to the IT domain by stating personal innovativeness is embodiment of individual's risk-taking propensity that only exists in certain individuals and not in others.

Marketing practitioners consider individual difference variables such as personal innovativeness as a critical concept for their campaign (Aroean \& Michaelidou, 2014). Since, the original UTAUT based theories failed to recognize role of individual differences during adoption process inclusion of this attribute is an important extension to meta-UATUT model. Within, mobile payment environment, Thakur and Srivastava (2014) found personal innovativeness as significant predictor of only existing mobile payment users' intentions and non-significant on non-user's intentions towards mobile payment adoption in India. In the meantime, Tan et al. (2014), found innovativeness as the most significant predictor of behavioural intentions to use near field communication mobile payment in Malaysia. As the mobile payment system is a relatively new way of payment in India, which is technologically different from other online methods of payment, it is strongly believed that consumer personal innovativeness will play a positive and significant role as far as their intentions to adopt the mobile payment is concerned. From the above discussion, the following hypothesis can be formulated:

H7. Personal innovativeness will have a positive and significant influence on consumer attitude to adopt mobile payment system.

\subsubsection{Anxiety}

Anxiety refers to the fear (e.g. sadness, perception and stress caused by stress-creating situations) experienced by an individual during their interaction with underlying computer technology (Simonson et al., 1987). In particular, anxiety refers to the fear about losing data or making any serious errors while using a technology (Venkatesh \& Davis, 2000). A significant body of research on IS/IT adoption has highlighted the relevance of anxiety on attitude, behavioural intention, and adoption (e.g., Celik, 2016; Igbaria, 1990; Korobili et al., 2010; Rana et al., 2016; Yang et al., 2020)

This research argues that anxiety adversely affects a consumer's attitude toward using the mobile payment system. In other words, consumers' positive belief toward mobile payment would be leveraged by reducing their anxiety. For example, Igbaria (1990) found that individuals with a high level of computer anxiety had a negative attitude toward using computer technology. Similarly, Korobili et al. (2010) found a strong and negative relationship between anxiety and attitude. Although the relationship between anxiety and attitude has been explored extensively in the technology adoption literature, hardly any research has examined this relationship in the context of mobile payment adoption. Therefore, the following hypothesis is formulated:

H8. Anxiety will have a negative and significant influence on consumer attitude. 


\subsubsection{Trust in mobile payment system}

Trust refers to subjective belief that a party will fulfil their obligations and plays a crucial role in electronic financial transactions, where users are exposed to larger risks due to uncertainty of the environment and sense of loss of control (Lu et al., 2011; Zhou, 2013). Trust also plays central role in determining future action between two or more parties and establishing relationships, both of interpersonal and commercial nature (McKnight \& Chervany, 2001; Sharma \& Sharma, 2019; Waseem et al., 2018). In other words, trust provides a subjective guarantee that consumers obtain a positive experience about the ability, honesty and goodwill of mobile payment service providers. That is, if the consumers do not build trust in mobile payment service providers, they cannot gain a convincing experience (Zhou, 2013). The online environment characteristics such as anonymity and lack of social cues due spatial separation amplifies the role of trust (Zhou, 2012).

Researchers have always found it difficult to define 'trust' historically and treated the construct both as unitary and multi-dimensional concept (McKnight et al., 2002). Trust have gained significant support as a unitary construct on consumer behavioural intention within mobile payment context (Lu et al., 2011; Shaw, 2014; Shin, 2010; Srivastava et al., 2010). Some of these studies (e.g., Shin, 2010; Srivastava et al., 2010) found trust as the most significant predictor of behavioural intention superseding the traditionally known dominant technology acceptance factors such as perceived usefulness. Liébana-Cabanillas et al. (2014b) and Lu et al. (2011) found that greater trust in the payment system concerned would significantly improve the users' attitude towards its use. Realising the increasing significance of trust in the context of mobile payment and the handful of research demonstrating how trust in the mobile payment systems could improve consumers' positive attitude toward transacting through it, this research proposes the following hypothesis:

H9. Trust in mobile payment system will have a positive and significant influence on consumer attitude.

\subsubsection{Grievance redressal}

Grievance redressal is one of the mechanisms focused on addressing consumers' grievances, issues and problems and getting them resolved by the mobile payment service providers. It provides an enormous benefit to consumers by resolving their problems post purchasing without much hassle (Rana et al., 2016). Only one research study in the area of analysing adoption of mobile wallet has covered the significance of the grievance redressal mechanism for failed transactions that are likely to influence mobile payment and m-wallet services (Kumar et al., 2018). The authors found that the grievance redressal system had a positive and significant influence on users' continued intention to use mobile wallet in India. This research believes that as redressing grievance is a post-purchase behaviour, the influence of grievance redressal should have a positive and significant influence on consumers' use behaviour of the mobile payment system. Therefore, the following hypothesis can be formulated based on the above discussion:

H10. Grievance redressal will have a positive and significant influence on consumers' use behaviour.

\subsubsection{Attitude toward using mobile payment systems}


Attitude is the degree to which consumers have a positive or negative evaluation about the behaviour in question (Ajzen, 1991). This construct has been used across prominent theories of IS/IT adoption including TRA (Fishbein \& Ajzen, 1975), TAM (Davis et al., 1989) and DTPB (Taylor \& Todd, 1995) to evaluate its influence on behavioural intentions. These models postulate that an individual's intention is determined by their attitude toward using the system (Davis et al., 1989; Fishbein \& Ajzen, 1975; Taylor \& Todd, 1995). Despite the major role of attitude among UTAUT guiding theories, the final UTAUT model excluded the construct. The meta-UTAUT argued this is significant departure and demonstrated reinstating attitude in the model could improve variance of the model in understanding consumer use of technology (Dwivedi et al., 2019). Numerous studies (Schierz et al., 2010; Wulandari, 2017) within mobile payment environment have endorsed the significant relationship between attitude and behavioural intention. For instance, Schierz et al. (2010) found a significant and positive relationship between consumer attitude and intention towards using the mobile payment service in Germany. Given the preceding discussion and considering that mobile payment is at infancy in India, this study proposes following hypothesis:

H11. Attitude towards using the mobile payment service will have a positive and significant influence on consumers' intention to use it.

\subsubsection{Behavioural intentions to use mobile payment systems}

Behavioural intention is an integral part of UTAUT2 model, which represents the extent of individuals willingness and effort to perform the underlying behaviour. Researchers assume intention could possibly capture various motivational factors of individuals that influence them to perform a behaviour. Therefore, stronger the intentions of individuals, higher the chances of performing the underlying behaviour (Ajzen, 1991). Dwivedi et al.'s (2011) meta-analysis on UTAUT found significant relationship for behavioural intention to use behaviour path relationship for all the eight studies in their examination. Majority of the existing studies (e.g., Alaeddin et al., 2018; Bailey et al., 2017; Kumar et al., 2018; Wulandari, 2017) have only studied consumers' intention to adopt mobile payments as an outcome variable.

Prior research has argued that behavioural intention is a good surrogate for use behaviour. But, researchers have also warned measuring use behaviour without assessing the actual use of any IS/IT (Wu \& Du, 2012). Researchers generally do not employ use behaviour in their model, due to a lack of consistent measurement items to collect responses on this construct. For example, Venkatesh et al. (2012), in their UTAUT2 model, used measurement items based on the usage frequency of various systems (e.g. ring tone and logo downloads, Java games, Mobile email etc.). However, some other studies (e.g., Sivathanu, 2019; Zhou et al., 2010) used the items for use behaviour on a normal Likert scale. As the area of research on mobile payment is slowly moving towards maturity and given that this research has gathered data from the existing users of mobile payment systems, it is only timely to assess their use behaviour as well. Some contemporary research (e.g., Sivathanu, 2019) on digital payment has assessed the influence of behavioural intention on use behaviour. For example, while investigating the actual use of digital payment systems in India, Sivathanu (2019) found the influence of behavioural intention on use behaviour as the most significant relationship in the model. As there is no research study that examines the impact of this relationship for mobile payment adoption and there is ample evidence for a significant impact of behavioural intention on use behaviour in the adoption of related technology, the following hypothesis was formulated: 
H12. Consumer behavioural intention to adopt the mobile payment system will have a positive and significant influence on their use behaviour.

\section{Research methodology}

Quantitative survey methodology was deemed appropriate for this investigation as validated scales from existing mobile payment adoption studies were readily available to measure the latent constructs (Rana et al., 2013; Slade et al., 2015b). The survey instrument started with a cover letter followed by two overarching sections. The first section comprised contextual items asking questions about respondents' knowledge on mobile payments and demographic characteristics. The second section consisted of measurement items (see Appendix 1), which were selected through literature review from studies with similar constructs as current study. Latent constructs were indirectly measured through the measurement items by deploying survey comprising of seven-point Likert scale with scores ranging from 1(="Strongly disagree”) to 7(=“Strongly agree”). Researchers validated the questionnaire using two steps: expert evaluation and pilot testing to rectify any problems before data collection and determine time required for survey completion. Saunders et al. (2007) recommend that a draft of the questionnaire should be sent to a panel of experts for critical evaluation. The experts should be asked to validate the content of the questions (Hair et al., 2010). Researchers distributed the questionnaire to experts from Indian Institute Technology Delhi (IITD), an elite higher education institution in India to evaluate survey instrument as this research focused on Indian context. Second, a pilot study was conducted among 34 Indian students to ensure the readability of the survey questions (Bhattacherjee, 2012; Dwivedi \& Williams, 2008; Saunders et al., 2007; Weerakkody et al., 2017). After careful consideration based on the pilot respondents' feedback minor changes were made to the wording of some questions.

Mobile payment is an emerging technology in Indian context and there is no reliable sampling frame for Indian users. While collecting data by electronic method allows for faster distribution of a survey at a relatively low-cost it can lead to sample selection bias by excluding anyone without internet (Bhattacherjee, 2012). In addition, many mobile payment and mobile banking studies in IS research have collected data from student populations that can increase selection bias (Chong, 2013). In order to minimise selection bias and maximise the number of respondents researchers distributed survey instrument using both paper-print and web-based survey approaches (Evans \& Mathur, 2005). Furthermore, researchers employed convenient sampling technique to garner response from general public in their social network (Saunders et al., 2007). Because collecting data only from student population will affect the generalisability of the result and excluding students might not represent the target population (Bhattacherjee, 2012). Researches distributed online survey link through social networking sites, and to staff and students of two educational institutions in India via email. Meanwhile, the paper-based surveys were distributed to students through the lectures of the educational institution. The survey questions were designed to screen the eligibility of the respondents right at the beginning, and web-based survey was designed to automatically terminate in case the respondent fail to meet the eligibility criterion. This study is also prone to common method bias (CMB) arising from self-reported nature of survey, asking participants to recall their mobile payment experience, common scale format of constructs, and respondents answering a question pertaining to both independent and dependent variables at same time (Podsakoff et al., 2003). Therefore, researchers conducted Harman's single-factor test, which is the most 
common method to examine CMB (Malhotra et al., 2006). The cumulative variance extracted value of $35.076 \%$, in Harman's single factor test was well below the threshold of $50 \%$ indicating the absence of common method bias.

Structural equation modelling (SEM), a second-generation statistical analysis technique, was used to analyse survey responses. SEM allows testing of all relationships between observed and latent variables simultaneously at the same time by combining multiple regression with factor analysis, and provides overall fit statistics (Iacobucci, 2009; Tabachnick \& Fidell, 2007). In addition, SEM is able to take measurement error with observed variables into account (Gefen et al., 2000; Hair et al., 2006). In comparison, first generation statistical techniques such as linear regression can only test relationships with one dependent variable at a time, yielding less than accurate results for mediated relationships (Iacobucci, 2009). Therefore, SEM has become the preferred technique for most theory testing studies particularly in IS/IT adoption research (Kim et al., 2010; Lu et al., 2011). Since this research aims to test a proposed model (with multiple dependent variables) and corresponding hypotheses, in order to have strong rigour in results, it was deemed appropriate to utilise SEM as an advanced inferential analysis technique for this research. AMOS v.22 was utilised as it is covariance-based SEM (Blunch, 2012) and was readily available in the researcher(s) institution. Prior to running actual SEM, the data was subjected to several stages of preliminary checks to ensure cleanliness and appropriateness of the data. The structural equation modelling followed Anderson and Gerbing (1988), two-step approach, which involves confirmatory factor analysis of the measurement model and path analysis of structural models.

\section{Results}

\subsection{Descriptive statistics}

This study collected 655 usable responses in total, 445 through an online survey questionnaire and the remaining 210 through paper-based questionnaire. Preliminary analysis revealed 164 responses had z-score beyond the range of $(-3,3)$ and hence removed from further analysis to ensure there are no outlier, yielding final test sample of 491 surveys. Unlike other studies in this area, the sample consisted higher proportion of females than males. In terms of age, majority of the respondents were younger with more than half of them $54.8 \%$ in the $18-24$ age group. Understandably, students emerged as the major occupation of respondents with $63.5 \%$ followed by private sector employees in second place with 24\% (Table 1).

Table 1: Descriptive characteristics of respondents

\begin{tabular}{|l|l|c|c|c|}
\hline Variable & Group & Frequency & Percentage & $\begin{array}{c}\text { Cumulative } \\
\text { Percent }\end{array}$ \\
\hline \multirow{5}{*}{ Age (Years) } & $18-24$ & 269 & 54.8 & 54.8 \\
\cline { 2 - 5 } & $25-29$ & 108 & 22.0 & 76.8 \\
\cline { 2 - 5 } & $30-34$ & 47 & 9.6 & 86.4 \\
\cline { 2 - 5 } & $35-39$ & 25 & 5.1 & 91.5 \\
\cline { 2 - 5 } & $40-44$ & 26 & 5.3 & 96.8 \\
\cline { 2 - 5 } & $45-49$ & 6 & 1.2 & 98.0 \\
\cline { 2 - 5 } & $50-54$ & 5 & 1 & 99.0 \\
\cline { 2 - 5 } & $55-59$ & 3 & 0.6 & 99.6 \\
\cline { 2 - 5 } & Above 60 & 2 & 0.4 & 100.0 \\
\hline \multirow{5}{*}{ Gender } & Male & 186 & 37.9 & 37.9 \\
\cline { 2 - 5 } & Female & 305 & 62.1 & 100.0 \\
\hline \multirow{5}{*}{ Occupation } & Student & 15 & 63.5 & 63.5 \\
\cline { 2 - 5 } & Unemployed & 1 & 0.2 & 66.6 \\
\cline { 2 - 5 } & Pensioner & & & 66.8 \\
\hline
\end{tabular}




\begin{tabular}{|c|c|c|c|c|}
\hline & Employee-Public Sector & 26 & 5.3 & 72.1 \\
\hline & Employee-Private Sector & 118 & 24 & 96.1 \\
\hline & Self-Employed & 19 & 3.9 & 100.0 \\
\hline \multirow[t]{4}{*}{ Handset } & Android based smartphone & 411 & 83.7 & 83.7 \\
\hline & IOS based smartphone & 76 & 15.5 & 99.2 \\
\hline & Microsoft based smartphone & 3 & 0.6 & 99.8 \\
\hline & $\begin{array}{l}\text { Simple basic mobile handset } \\
\text { without touchscreen }\end{array}$ & 1 & 0.2 & 100.0 \\
\hline \multirow{3}{*}{$\begin{array}{l}\text { Would you use mobile } \\
\text { payment system, if there were } \\
\text { a financial incentive over other } \\
\text { payment methods? }\end{array}$} & Yes & 416 & 84.7 & 84.7 \\
\hline & No & 48 & 9.8 & 94.5 \\
\hline & Unsure & 27 & 5.5 & 100.0 \\
\hline \multirow{7}{*}{$\begin{array}{l}\text { How long have you been using } \\
\text { mobile payment systems? }\end{array}$} & Less than a year & 28 & 5.7 & 5.7 \\
\hline & 1-2years & 16 & 3.3 & 9 \\
\hline & 3-4years & 64 & 13 & 22 \\
\hline & 5-6years & 216 & 44 & 66 \\
\hline & 7-8years & 131 & 26.7 & 92.7 \\
\hline & 8-10years & 24 & 4.9 & 97.6 \\
\hline & More than 10 years & 12 & 2.4 & 100 \\
\hline
\end{tabular}

Android based smartphones emerged as the most preferred operating system among Indian consumers with astonishing $83.7 \%$ using them, followed by IOS based smartphone at distant second at $15.5 \%$. Interestingly, an astounding $84.7 \%$ of respondents said that they would use mobile payment system, if there were a financial incentive over other payment methods. Finally, there were $78 \%$ respondents cumulatively who were using mobile systems for more than five years (Table 1 ).

\subsection{Measurement model}

Confirmatory factor analysis (CFA) test was conducted to verify the measurement model by examining convergent validity, discriminant validity, and internal consistency of the constructs (Slade, 2015b). This research adapted Anderson and Gerbing (1988), three ad hoc tests such as standardised factor loadings, composite reliabilities, and average variance extracted to estimate the convergent validity of latent variables. The standardised factor loadings values ranged from 0.60 to 0.92 generating value higher than required 0.50 cut-off (Gefen et al., 2000). Meanwhile, the composite reliability values demonstrated internal consistency of the latent constructs with values above the threshold of 0.70 (Hair et al., 1992; Nunnally, 1978). Finally, average variance extracted (AVE) values, which are a measure of variation explained by the latent variable to random measurement error ranged from 0.67 for facilitating conditions to 0.90 for attitude (AT) much higher than the stipulated lower limit of 0.50 (Fornell \& Larcker, 1981) (see Table 2). The latent construct qualified convergent validity test with values higher than the stipulated threshold across the Anderson and Gerbing (1988) three tests.

Table 2: Results of confirmatory factor analysis (CFA)

\begin{tabular}{|l|c|c|c|}
\hline Construct & FL & CR & AVE \\
\hline Use Behaviour & & 0.81 & 0.69 \\
\hline UB1 & 0.73 & & \\
\hline UB2 & 0.73 & & \\
\hline UB3 & 0.60 & & \\
\hline UB4 & 0.82 & & \\
\hline Performance Expectancy (PE) & & 0.87 & 0.81 \\
\hline PE1 & 0.85 & & \\
\hline PE2 & 0.78 & & \\
\hline PE3 & 0.73 & & \\
\hline
\end{tabular}




\begin{tabular}{|l|c|c|c|} 
PE4 & 0.81 & & \\
\hline Effort expectancy (EE) & & 0.90 & 0.86 \\
\hline EE1 & 0.81 & & \\
\hline EE2 & 0.83 & & \\
\hline EE3 & 0.84 & & \\
\hline EE4 & 0.78 & & \\
\hline EE5 & 0.78 & & \\
\hline Social Influence (SI) & & 0.89 & 0.87 \\
\hline SI1 & 0.91 & & \\
\hline SI2 & 0.88 & & \\
\hline Facilitating Conditions (FC) & & 0.80 & 0.67 \\
\hline FC1 & 0.81 & & \\
\hline FC2 & 0.84 & & \\
\hline FC3 & 0.60 & & \\
\hline FC4 & 0.54 & & \\
\hline Behavioural Intention (BI) & & 0.88 & 0.84 \\
\hline BI1 & 0.87 & & \\
\hline BI2 & 0.90 & & \\
\hline BI3 & 0.74 & & \\
\hline Attitude (AT) & & 0.91 & 0.88 \\
\hline AT1 & 0.78 & & \\
\hline AT2 & 0.85 & & \\
\hline AT3 & 0.85 & & \\
\hline AT4 & 0.87 & & \\
\hline AT5 & 0.76 & & \\
\hline Trust (TR) & & 0.92 & 0.90 \\
\hline TR1 & 0.85 & & \\
\hline TR2 & 0.93 & & \\
\hline TR3 & 0.89 & & \\
\hline Anxiety (ANX) & & 0.91 & 0.88 \\
\hline ANX1 & 0.81 & & \\
\hline ANX2 & 0.81 & & \\
\hline ANX3 & 0.83 & & \\
\hline ANX4 & 0.92 & & \\
\hline Personal Innovativeness (PIN) & & 0.83 & 0.74 \\
\hline PIN1 & 0.61 & & \\
\hline PIN2 & 0.75 & & \\
\hline PIN3 & 0.88 & & \\
\hline PIN4 & 0.73 & & \\
\hline Grievance redressal (GR) & & 0.90 & 0.87 \\
\hline GR1 & 0.84 & & \\
\hline GR2 & 0.90 & & \\
\hline GR3 & 0.86 & & \\
\hline & & & \\
\hline
\end{tabular}

[Legend: AVE=Average Variance Extracted, CR=Composite Reliability, FL=Factor Loading]

Furthermore, latent constructs satisfy discriminant validity test when square roots of AVE values for each factor is greater than the inter-construct correlations in the factor correlation matrix. The discriminant validity test results depicted in Table 3 revealed that the square root of AVE values shown in bold across the diagonals is always greater than the construct correlations among corresponding pair of variables. For example, the inter-correlation (i.e. 0.699) between $\mathrm{PE}$ and $\mathrm{EE}$ is always less than the square root of AVE values for PE (i.e. 0.901) and EE (i.e. 0.926). This is satisfied for every correlation between the variables of the proposed research model presented indicating that discriminant validity for constructs is also satisfied. 
Table 3: Factor correlation matrix

\begin{tabular}{|c|c|c|c|c|c|c|c|c|c|c|c|c|c|}
\hline VAR & CR & AVE & PE & EE & SI & FC & $\mathbf{A T}$ & BI & UB & TR & ANX & PIN & GR \\
\hline PE & 0.872 & 0.811 & 0.901 & & & & & & & & & & \\
\hline EE & 0.904 & 0.860 & $.699^{* *}$ & 0.926 & & & & & & & & & \\
\hline SI & 0.890 & 0.866 & $.215^{* *}$ & .087 & 0.931 & & & & & & & & \\
\hline FC & 0.797 & 0.671 & $.561^{* *}$ & $.636^{* *}$ & $.069^{*}$ & 0.819 & & & & & & & \\
\hline AT & 0.913 & 0.877 & $.627^{* *}$ & $.614^{* * *}$ & $.143^{* *}$ & $.577^{* *}$ & 0.937 & & & & & & \\
\hline BI & 0.877 & 0.835 & $.652^{* *}$ & $.598^{* *}$ & $.232^{* *}$ & $.547^{* *}$ & $.738^{* *}$ & 0.914 & & & & & \\
\hline UB & 0.811 & 0.693 & $.628^{* *}$ & $.627^{* *}$ & $.101^{*}$ & $.512^{* *}$ & $.538^{* *}$ & $.534^{* * *}$ & 0.833 & & & & \\
\hline TR & 0.920 & 0.901 & $.482^{* *}$ & $.457^{* *}$ & $.264^{* *}$ & $.455^{* *}$ & $.663^{* *}$ & $.537^{* * *}$ & $.421^{* * *}$ & 0.949 & & & \\
\hline ANX & 0.908 & 0.876 & -.047 & $-.107^{*}$ & $.269^{* *}$ & -.069 & $-.119^{* *}$ & $-.096^{*}$ & -.066 & -.084 & 0.936 & & \\
\hline PIN & 0.834 & 0.741 & $.381^{* *}$ & $.321^{* *}$ & $.305^{* *}$ & $.271^{* *}$ & $.472^{* *}$ & $.447^{* *}$ & $.356^{* *}$ & $.481^{* *}$ & $.148^{* *}$ & 0.861 & \\
\hline GR & 0.901 & 0.872 & $.371^{* *}$ & $.418^{* *}$ & $-.100^{*}$ & $.426^{* *}$ & $.465^{* *}$ & $.395^{* *}$ & $.367^{* *}$ & $.300^{* * *}$ & $-.101^{*}$ & $.230^{* *}$ & 0.934 \\
\hline
\end{tabular}

[Note: CR=Composite Reliability; AVE = Average Variance Extracted; PE=Performance Expectancy; EE=Effort Expectancy; SI=Social Influence; FC=Facilitating Conditions; AT=Attitude; BI=Behavioural Intention; UB=User Behaviour; VAR: Variable; TR=Trust; ANX=Anxiety; PIN=Personal Innovativeness; GR= Grievance; $\sqrt{A V E}$ is shown in italics on the diagonal, $\left.\mathrm{p}^{*}<0.05 ; \mathrm{p}^{* *}<0.01 ; \mathrm{p}^{* * *}<0.001\right]$

Overall measurement model fit was determined through assessment of five common measures: normed Chi-Square (CMIN/DF), Adjusted Goodness of Fit Index (AGFI), Comparative Fit Index (CFI), Root Mean Square Error of Approximation (RMSEA), and Parsimonious Normed Fit Index (PNFI). The measurement model is deemed sufficiently fit when these measures are $<3, \geq 0.80, \geq 0.90, \leq 0.06$, and $>0.50$ respectively (Hair et al., 2006; Hu \& Bentler, 1999). The overall measurement model fit indices test resulted in $\chi^{2}$ value of 1357.456 with degree of freedom of 714.00 and Chi-Square to degree of freedom of 1.901. The Chi-Square/DF value was found to be less than 3.0 - which is within the suggested [3-1] bracket (Chin \& Todd, 1995; Gefen et al., 2000). The remaining fit indices such as AGFI=0.855, CFI $=0.955$, RMSEA $=0.043$, and PNFI $=0.793$ were well within their expected threshold value reassuring the fitness of measurement model for further analysis.

\subsection{Structural model}

Structural equation modelling (SEM) analysis was conducted using AMOS Graphics and SPSS Version 25.0 software. Prior to path analysis of the proposed model, it is necessary to establish adequate model fit indices of the structural model. Structural model fit indices estimation revealed satisfactory results, with $\chi^{2}$ value of 1996.547 and 756 degrees of freedom yielding desirable Chi-square to degree of freedom ratio of 2.641. The remaining fit indices such as AGFI $=0.810$, CFI $=0.913$, RMSEA $=0.058$, and PNFI $=0.800$ were reported to be well within their expected threshold values. After establishing adequate structural model fit indices, it is appropriate to conduct path analysis. This study found support for all the twelve proposed hypotheses corresponding from H1 to H12. Significant positive relationship were observed between dependent variable attitude and its predictors performance expectancy, effort expectancy, personal innovativeness, and trust (confirming H1, H3, H7, and H9). Meanwhile, the final predictor anxiety emerged as significant negative predictor of Indian consumers attitude towards mobile payment (confirming H8). Subsequently, attitude served as significant positive predictor of behavioural intention by mediating the effects of above mentioned various exogenous variables and thus confirmed H11. In addition to attitude, social influence and facilitating conditions emerged as significant direct positive predictors of behavioural intention (confirming $\mathrm{H} 4$ and $\mathrm{H} 5$ ). Apart from behavioural intention, facilitating conditions also had significant positive relationship with effort expectancy (conforming H6). 
Table 4. Hypothesis test results

\begin{tabular}{|c|c|c|c|c|c|c|}
\hline Hypothesis & Independent Construct & $\begin{array}{l}\text { Dependant } \\
\text { Construct }\end{array}$ & $\mathrm{R}^{2}$ & $\begin{array}{c}\text { Path } \\
\text { coefficient }\end{array}$ & $\begin{array}{c}\mathrm{p}^{-} \\
\text {Values }\end{array}$ & $\begin{array}{c}\text { Hypothesis } \\
\text { Support? }\end{array}$ \\
\hline H6 & Facilitating Conditions & $\begin{array}{l}\text { Effort } \\
\text { expectancy }\end{array}$ & 0.70 & 0.837 & 0.000 & Yes \\
\hline $\mathrm{H} 1$ & Performance Expectancy & \multirow[t]{5}{*}{ Attitude } & \multirow[t]{5}{*}{0.59} & 0.273 & 0.000 & Yes \\
\hline H3 & Effort expectancy & & & 0.323 & 0.000 & Yes \\
\hline H8 & Anxiety & & & -0.099 & 0.006 & Yes \\
\hline H9 & Trust & & & 0.405 & 0.000 & Yes \\
\hline H7 & Personal Innovativeness & & & 0.198 & 0.000 & Yes \\
\hline H11 & Attitude & \multirow{3}{*}{$\begin{array}{l}\text { Behavioural } \\
\text { Intention }\end{array}$} & \multirow[t]{3}{*}{0.66} & 0.613 & 0.000 & Yes \\
\hline $\mathrm{H} 4$ & Social Influence & & & 0.163 & 0.000 & Yes \\
\hline H5 & Facilitating Conditions & & & 0.261 & 0.000 & Yes \\
\hline $\mathrm{H} 2$ & Performance Expectancy & \multirow{3}{*}{$\begin{array}{l}\text { Use } \\
\text { behaviour }\end{array}$} & \multirow[t]{3}{*}{0.50} & 0.542 & 0.000 & Yes \\
\hline H12 & Behavioural Intention & & & 0.231 & 0.000 & Yes \\
\hline H10 & Grievance redressal & & & 0.162 & 0.000 & Yes \\
\hline
\end{tabular}

[Legend: Significance of $\mathrm{p}-$ Value: $\mathrm{p}>0.05(\mathrm{~N} . S)$ : Non-significant; $\mathrm{p}<0.05$ : ${ }^{*} ; \mathrm{p}<0.01$ : $^{* *} ; \mathrm{p}<0.001$ : $^{* * *} ; \mathrm{R}^{2}$ : Variance explained]

Finally, the ultimate dependant variable use behaviour had three significant positive predictors such as performance expectancy, behavioural intention, and grievance redressal confirming the hypotheses $\mathrm{H} 2, \mathrm{H} 12$, and $\mathrm{H} 10$ respectively. In terms of significant paths, facilitating conditions was the strongest predictor of effort expectancy with path coefficient value of 0.837 and as predicted attitude was the strongest predictor of behavioural intention with path coefficients value of 0.613 . Meanwhile, performance expectancy with path value of 0.542 emerged as the strongest predictor of Indian consumer use behaviour towards mobile payment. The final validated model reveals path coefficients and significance of each path relationship alongside the variance explained by various exogenous constructs on each of the four endogenous constructs (effort expectancy, attitude, behavioural intention, and use behaviour) (Figure 2 and Table 4). It is also worth noting that facilitating conditions had the strongest influence on effort expectancy, explaining about $70 \%$ of the variance on the construct. Likewise, all significant relationships on attitude, behavioural intentions, and use behaviour explained about 59\%, 66\% and $50 \%$ of the variance respectively. 


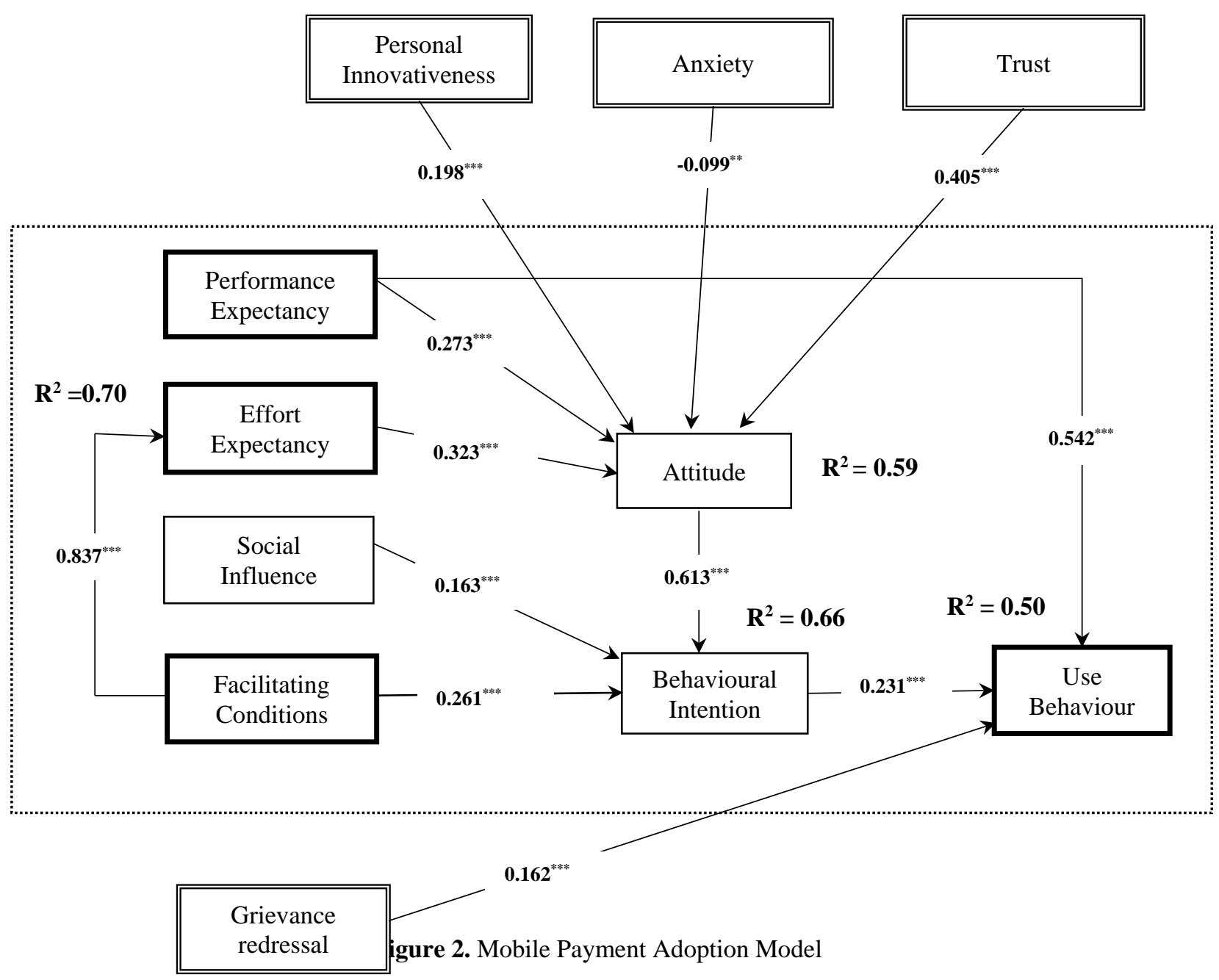

Meta-UTAUT $\square$ New Internal mechanism

New Endogenous mechanism

\section{Discussion}

This study employed an extended meta-UTAUT model as theoretical lens to investigate Indian consumers mobile payment adoption. The proposed model comprised of seven exogenous variables (i.e. performance expectancy, social influence, facilitating conditions, personal innovativeness, anxiety, trust, and grievance redressal) and four endogenous variables (i.e. effort expectancy, attitude, behavioural intentions, and use behaviour) related through twelve path relationships (H1-H12). Structural equation modelling found all the twelve proposed hypotheses as significant and thereby providing further support to some of the existing UTAUT relationships in a modern consumer technology context. The current model explained variance of $66 \%$ on Indian consumer behavioural intention towards mobile payment adoption, which is comparable to studies that explained similar variance on behavioural intention such as $66 \%$ in Qatar (Alshare \& Mousa, 2014), 67.5\% in India (Gupta et al., 2019), and 67\% in the UK (Slade et al., 2015b) based on UTAUT model. However, none of these studies measured use behaviour as outcome variable and the influence of attitude on consumer adoption towards mobile payment. Therefore, this research is a step forward in filling this gap using the extended meta- 
UTAUT model and explaining about $59 \%$ and $50 \%$ of variance on Indian consumer attitude and use behaviour towards mobile payment respectively.

Concurrent to existing research on mobile payment adoption (e.g., Alaeddin et al., 2018; Shaikh et al., 2018), the role of performance expectancy emerged as significant predictor of Indian consumers attitude towards mobile payment. The results confirm that utilitarian assistance of m-payment is an important aspect in shaping consumers' positive attitude to adopt. Although the relationship between PE and attitude was found significant at the $\mathrm{p}<0.001$ level, the influence is weaker than expected. In this research PE influences attitude only with a coefficient of 0.273 emerging only as the sixth strongest relationship. This finding is very different to PU and attitude findings provided by Davis et al. (1989), research where they analysed the influence of PU on attitude and suggested the coefficient between these variables to be greater than 0.50 . Instead, performance expectancy had strong impact on use behaviour with path value of 0.542 to emerge as the third strongest relationship in the entire model. This clearly indicates that perceived utilitarian benefits of the experienced consumers directly influence their actual use behaviour of mobile payment systems.

Moreover, effort expectancy, a construct like perceived ease of use, was found significant positive predictor of attitude (H3) reaffirming this relationship in the consumer m-payment domain (e.g., Shaikh et al., 2018). Prior research found EE as a significant factor among users only during early stages of technology adoption with lower education levels who are more sensitive to the ease of using a service (Venkatesh \& Davis, 2000). However, the current research findings demonstrate that effort expectancy is equally important for the existing users for relatively new and cutting-edge technology such as mobile payment applications to keep the users interested and engaged via easy to use interface. Given that there are more than 2.1 million apps available to Android users followed closely by Apple with more than 2 million apps (Statistica, 2018), the consumers need to be experts in using various apps. In that vein, the relevance of the app interface and their easiness to use are important to shape a positive attitude of consumers to use them.

In addition to performance expectancy and effort expectancy, three other constructs such as: anxiety, personal innovativeness, and trust also emerged as the significant predictors of Indian consumer attitude towards mobile payment. Trust emerged as the strongest predictor of attitude with TR $\rightarrow$ AT $\left(0.405^{* * *}\right)$ path value amongst all the five antecedents. Literature review on UTAUT suggests trust as one of the most common extensions of the model (Williams et al., 2015). Numerous studies around the globe have confirmed significant positive impact of trust on consumer attitude towards m-payment adoption such as Turkey (Daştan \& Gürler, 2016) and Brazil (Giovannini et al., 2015) to list a few. Therefore, trust in the m-payment services allows the consumers to positively start thinking about using such a system. Meanwhile, personal innovativeness emerged as significant positive predictor of attitude, as mobile payment is a relatively new and innovative way of payment to Indian consumers, and technologically different to other online methods of payment. Majority of existing studies have explored the significant impact of innovativeness on behavioural intention around the such as China (Yang et al., 2012), Taiwan (Cheng \& Huang, 2013), Malaysia (Tan et al., 2014), and India (Thakur \& Srivastava, 2014). However, not many studies have analysed the impact of personal innovativeness on attitude. For Instance, Thakur and Srivastava (2014) found the impact of personal innovativeness as significant predictor of Indian consumers intention towards mobile payment only for experienced users and non-significant for non-users. Since, this research gathered only from existing users of the m-payment system, the findings of current study are consistent with Thakur and Srivastava (2014), findings on users. This indicates Indian 
consumers with higher levels of personal innovativeness are expected to develop more positive beliefs towards m-payment.

Despite the significant positive effects of above mentioned four antecedents such as: performance expectancy, effort expectancy, personal innovativeness, and trust on attitude, the fifth antecedent anxiety emerged as the significant and only negative predictor of Indian consumers attitude towards mobile payment adoption. Numerous studies within information systems and psychology arena support the negative influence of anxiety on individuals' attitude towards technology adoption (e.g., Howard \& Smith, 1986; Igbaria, 1990). Igbaria (1990), argued that individuals with a high level of computer anxiety will have a negative attitude toward using a computer. The weakest value for ANX $\rightarrow$ AT $(-0.099 * *)$ path indicates the influence of anxiety is not that strong to have serious impact on consumer attitude to use the m-payment system. However, the negative and significant impact of anxiety on attitude clearly shows that no matter how long consumers have the experience in using mobile payment systems, they will always have a sense of anxiety, apprehension and fear when they use mobile payment.

Behavioural intention, the core mediating variable of individual use behaviour towards technology adoption, had three antecedents' such as attitude, social influence, and facilitating conditions. The results revealed all three antecedents as significant and positive predictors of Indian consumers intention towards mobile payment. Though, social influence was found as significant predictor of behavioural intention, the effect was weakest among all UTAUT relationships with path value 0.163 , like some of the existing studies in this area (Slade et al., 2015a, 2015b). The support for this relationship indicates that belief of referent others influences Indian consumers' intentions to adopt m-payment systems. For example, KoenigLewis et al. (2015) demonstrated users of m-payment are sensitive to social influence and consider their friends' expectations when using a technology is concerned.

In terms of facilitating conditions, numerous existing studies (e.g., Morosan \& DeFranco, 2016; Sivathanu, 2019) have confirmed the significant role of the construct on consumer intention towards technology adoption within payment environment. While Morosan and DeFranco (2016) found facilitating conditions to exert a significant impact on consumers' behavioural intentions to use near field communication-mobile payments in hotels in the USA. Sivathanu (2019) found that facilitating conditions to have positive influence on Indian consumer behavioural intention towards digital payment systems. However, some other studies (e.g., Baptista \& Oliveira, 2015; Slade et al., 2015a) have also found this relationship to be nonsignificant. The significance of this relationship in the current study explains the necessity of resources, technical, and institutional support to consumers for developing intention towards $\mathrm{m}$-payment system. Asides from intention, facilitating conditions emerged as significant predictor of effort expectancy making the $\mathrm{FC} \rightarrow \mathrm{EE}\left(0.837^{* * *}\right)$ path strongest in the entire model. Prior research has found support for significant relationship between facilitating conditions and effort expectancy or its proxy variable perceived ease of use. For instance, Stefi (2015) found facilitating conditions are expected to significantly lower software developers' effort when integrating existing components. Meanwhile, San-Martín et al. (2013) found facilitating conditions as one of the strongest predictors of ease of use while examining drivers and impediments of mobile shoppers in Spain. Therefore, this research argues that better resources, technical and institutional infrastructure can help consumers in better understanding and operating the m-payment system. 
Besides, social influence and facilitating conditions the remaining antecedent of behavioural intention, attitude also emerged as the significant positive predictor. However, attitude was the strongest predictor among all the three antecedents in determining Indian consumers behavioural intention towards mobile payment adoption with path value of AT $\rightarrow B I$ $\left(0.613^{* * *}\right)$. This reaffirms the role of including attitude in understanding individual technology and adapting meta-UTAUT model as theoretical lens for this research investigation. The inclusion of attitude in the proposed research model is consistent with the theory of reasoned action (Fishbein \& Ajzen, 1975), theory of planned behaviour (Ajzen, 1991), and decomposed theory of planned behaviour (Taylor \& Todd, 1995). Attitude has also been used as a mediating variable between performance expectancy and effort expectancy across several studies (e.g., Alshare \& Lane, 2011; Rana et al., 2017; Šumak et al., 2010) that have used UTAUT as a basic model.

Use behaviour, the outcome variable of this research investigation, had three antecedents such as performance expectancy, behavioural intention, and grievance redressal. As discussed, earlier performance expectancy emerged as the strongest predictor of behavioural intention with path value for PE $\rightarrow \mathrm{UB}\left(0.542^{* * *}\right)$. Meanwhile, behavioural intention, the most often used proxy variable for use behaviour, emerged as the second strongest predictor with path value for BI $\rightarrow$ UB (0.231***). Only a handful of studies (e.g., Escobar-Rodrguez et al., 2014; Salahshour Rad et al., 2019; Sivathanu, 2019) on technology and digital adoption have examined the influence of behavioural intention on use behaviour. As Indian consumers are habitual users of cash as it is a part of Indian culture (Sivathanu, 2019), the high degree of consumers' positive intent to use m-payment as a tool to pay for services, would likely incline towards actual use of such technology for their day-to-day use. Finally, grievance redressal had a positive and significant influence on consumers' use behaviour. It provides huge benefits to consumers by tackling their issues after purchasing their items (Rana et al., 2016; Weerakkody et al., 2007, 2009). These findings are consistent with Kumar et al.'s (2018) study, which found grievance redressal of failed transactions are likely to influence m-payment and m-wallet services. There is a need for more consumer awareness toward lodging grievances through appropriate channels when they have any such issue of failed transactions or receive damaged products.

\subsection{Theoretical contributions}

The major theoretical contributions of this study stems from empirical validation of extended meta-UTAUT model with context specific variables. In doing so, this study improves explanation of meta-UTAUT model as defined by Whetten (2009, p. 37) cross-context theorising framework through attributes specific to Indian context. None of the existing research on IS/IT adoption in general and on mobile payment adoption has validated metaUTAUT model. Hence, empirically testing this model is the primary theoretical contribution to adoption research in general with specific focus on mobile payment adoption.

Secondly, the comprehensive review of literature on mobile payment adoption also indicates that the proposed meta-UTAUT model does not have all context specific external constructs that could more appropriately capture the possible facets of mobile payment adoption, particularly in the context of India. Realising this gap, this research has included anxiety, trust, personal innovativeness, and grievance redressal as the additional constructs along the metaUTAUT model through new endogenous mechanism. This refers to association between external variables and any of the three meta-UTAUT endogenous variables such as attitude, intention, and usage. These additional variables have been considered along the meta-UTAUT model based on their use and relevance to the existing research on mobile payment adoption. 
In addition, researchers introduced new association between existing meta-UTAUT model variables such as facilitating conditions, effort expectancy, performance expectancy, and use behaviour through new internal mechanism, which refers to enrichment of existing metaUTAUT exogenous/endogenous variables through new association. These new extension mechanisms provide further contribution to the existing theory and can help future researchers understand the use of such a model to validate the mobile payment adoption in other developing countries that share a similar socio-economic nature as India.

Moreover, even though mobile payment is becoming a more mature research field, none of the existing empirical research has included the use behaviour construct to understand mobile payment adoption. This research is a step further along those line in contributing to the existing mobile payment literature by including use behaviour as outcome variable and validating the model by collecting appropriate data from the adopters of the mobile payment systems in the context of India.

\subsection{Implications for practice}

This research model offers holistic understanding on various drivers and inhibitors behind Indian consumer use behaviour towards mobile payment and offer number of implications for the practitioners. For instance, the significant impact of performance expectancy on attitude and use behaviour indicates that in the case of targeting Indian consumers, advertising messages should address the usefulness of mobile payment (Bailey et al., 2017). These relationships also indicate that companies should introduce a strong and reliable mobile payment system that could meet the consumers' expectation - particularly the expectations of technology enthusiasts (De Luna et al., 2019). As usefulness is a determining factor in the use of mobile payment systems, the mobile payment systems development companies should encourage developers to develop the system as per users' experience and go beyond their expectations. They should not only focus on the utility of the system but also add value to their use (Schierz et al., 2010).

Meanwhile, significant impact of effort expectancy on attitude indicates that systems developers should design user-friendly mobile applications to enhance consumers' belief in using them for payment purposes over any Internet enabled device (Bailey et al., 2017). This significant relationship also offers guidance to managers who look forward to enhancing the market share of their financial products such as mobile wallets that they should focus more on increasing the convenience of using mobile wallet and make it user-friendly, while its simplicity should also be associated with a high level of security to attract more consumers to use such systems (Alaeddin et al., 2018). The significance of social influence on behavioural intentions indicates that mobile payment providers should allocate resources and efforts towards more active use of societal influence to motivate consumers' behavioural intentions. The mobile service or app providers should advertise and encourage payment by mobile systems through celebrities and role models (particularly from cinema and sports) who have many fan followings so that consumers can believe their testimonials and start using such systems. Mobile service providers should also improve their use of social media to promote interpersonal word-of-mouth communications to increase the use of mobile applications by consumers (Slade et al., 2015b).

Further, the positive impact of facilitating conditions on effort expectancy and behavioural intentions indicates that mobile service providers should provide the training and support programmes, which may lead to better understanding and use of mobile apps by consumers. Designers of the mobile payment system can also provide an additional package of online 
training for the apps to ensure that consumers can see a demonstration or obtain relevant help required to use the system. Adequate resources available to consumers to use the mobile apps make the use of the system easier and increase their intent to use the apps. Moreover, mobile service providers can allocate more resources to training and user participation to make consumers familiar with the mobile payment systems (Venkatesh \& Bala, 2008). The significant impact of meta-UTAUT extension personal innovativeness on consumer attitude indicates that mobile service providers should focus on such consumer attributes. Therefore, mobile app retailers and service providers should encourage innovative Indian consumers to adopt mobile payments, to help reduce risks for other adopters through their social networks (Slade et al., 2015b).

The significant and negative influence of anxiety on attitude indicates that mobile app retailers and mobile payment service providers should do everything they can do to minimise consumer anxiety. For example, they should take special care of consumers who are of a traditional mindset and have just started to use the mobile payment system. For them anxiety due to unfamiliarity with the interface design and self-efficacy could be the main concern in being hesitant to use such a system (Czaja et al., 2006). The mobile commerce companies should also encourage electronic word of mouth and consumer engagement marketing (e.g. consumer reviews, blog contents etc.) practices to promote mobile shopping for consumers with high levels of anxiety about using mobile payment services (Yang \& Forney, 2013).

The significant effect of trust on attitude indicates that the mobile apps and commerce companies should promote trust by presenting clear return and privacy policies or by commissioning visual displays of security and quality certifications (Giovannini et al., 2015). They should emphasise trust-building activities, specifically in relation to the new ways of mobile payment such as NFC and proximity m-payments, which will further help reduce consumer perceptions of risk. The use of tokenisation - where original card and/or bank details are substituted by a discrete reference code - may also build trust in the system (Slade et al., 2015b). Finally, the positive and significant influence of grievance on consumer use behaviour indicates that mobile payment service providers must include a transparent grievance redressal mechanism with proper security measures to improve consumers' use of such services (Kumar et al., 2018). They should be promptly responding to consumers in case of failed mobile payment transactions and be able to promptly demonstrate transparency in settling claims for such failed transactions. If there are any legal disputes about the mobile payment, they must be resolved by the mobile payment service providers in a timely manner.

\subsection{Limitations and future research directions}

Like all other research, this research is also subject to reasonable limitations and shortcomings. Considering this, the research has identified the following limitations and directions for future research. Firstly, this research used a non-probability based convenient sampling method to collect the data from a few cities and via personally visiting places which mainly included universities for examining factors affecting mobile payment adoption in India. Such an approach is not uncommon and has been widely utilised in previous studies on adoption of a variety of technology. Given that respondents included in the sample had access to smartphones and were able to make mobile payments, non-probability sampling should not have made a substantial impact on the results of this study. However, it would be useful for future studies to employ probability sampling so a comparison can be made with studies that have employed non-probability sampling. Secondly, majority of the respondents for this research were educated students who are computer and internet literate. The questionnaire was in English 
language only. India is a country of multiple languages and cultures and collecting data only in one language restricts participants of other culture and languages. In future, data can be collected by a method which allows people from different language and education level to participate. Third, this research selected responses from only adopters of mobile payment technology in India. There is a need to perform research on non-adopters and analyse results using the model proposed in this research. Fourth, this research focused only on a quantitative approach which restricted the in-depth view of consumers to explore more on payment adoption. Due to time and resources constraints in depth research using a mixed method approach could not be conducted. Future studies can utilise a mixed method approach for further understanding. Finally, this research measure use behaviour through self-reported usage scale. Future studies should collect and analyse actual usage data.

\section{Conclusions}

This research is aimed to examine various factors affecting Indian consumers adoption and usage of mobile payment. First, researchers employed Dwivedi et al.'s (2019) meta-UTAUT model as theoretical lens and extended the model with constructs such as: personal innovativeness, anxiety, trust, and grievance redressal to be more relevant to consumer mobile payment context. Second, focused on India - the second largest mobile market in the world with 616 million subscribers (Gsmaintelligence, 2017). Finally, tested the model empirically among 491 respondents to identify significant determinants of Indian consumers use behaviour towards mobile payment. The results revealed three newly added constructs personal innovativeness, anxiety, and trust as significant indirect determinant of consumer use behaviour through attitude and behavioural intention. Meanwhile, the final new extension grievance redressal emerged as significant direct determinant of Indian consumer use behaviour towards mobile payment alongside performance expectancy and behavioural intention. Although performance expectancy impact was less on attitude, it emerged as the strongest predictor of use behaviour highlighting the utilitarian value provided by mobile payments to Indian consumers. This study also provided number of contributions to theory and practice.

\section{Appendix 1: Final survey measurements}

\begin{tabular}{|c|c|c|c|}
\hline Construct & Code & Item & Source \\
\hline \multirow[t]{4}{*}{ User Behaviour } & UB1 & I use mobile payment systems & \multirow[t]{4}{*}{ Sivathanu (2019) } \\
\hline & UB2 & I pay for purchases using mobile payment systems & \\
\hline & UB7 & $\begin{array}{l}\text { I use mobile payment systems for transferring } \\
\text { money to my family, friends and/or other contacts }\end{array}$ & \\
\hline & UB10 & $\begin{array}{l}\text { I use mobile payment systems when doing online } \\
\text { shopping }\end{array}$ & \\
\hline \multirow[t]{4}{*}{$\begin{array}{l}\text { Performance } \\
\text { Expectancy }\end{array}$} & PE2 & $\begin{array}{l}\text { Using mobile payment systems helps me accomplish } \\
\text { transaction (i.e. shopping, purchases, transfers etc) } \\
\text { more quickly }\end{array}$ & \multirow[t]{4}{*}{ Venkatesh et al. (2012) } \\
\hline & PE3 & $\begin{array}{l}\text { Using mobile payment systems increases my } \\
\text { productivity }\end{array}$ & \\
\hline & PE4 & $\begin{array}{l}\text { Using mobile payment systems makes it easier for } \\
\text { me to do transactions (i.e. shopping, purchases, } \\
\text { transfers etc.) }\end{array}$ & \\
\hline & PE5 & $\begin{array}{l}\text { Using mobile payment systems improves my overall } \\
\text { payment performance }\end{array}$ & \\
\hline \multirow[t]{3}{*}{ Effort Expectancy } & EE1 & I find mobile payment systems easy to use & \multirow[t]{3}{*}{ Venkatesh et al. (2012) } \\
\hline & EE2 & $\begin{array}{l}\text { My interaction with mobile payment systems is clear } \\
\text { and understandable }\end{array}$ & \\
\hline & EE3 & $\begin{array}{l}\text { It is easy for me to become skilful at using mobile } \\
\text { payment systems }\end{array}$ & \\
\hline
\end{tabular}




\begin{tabular}{|c|c|c|c|}
\hline & EE4 & I find mobile payment systems flexible to interact & \\
\hline & EE5 & $\begin{array}{l}\text { I find it easy to get mobile payment systems to do } \\
\text { what I want it to do }\end{array}$ & \\
\hline \multirow[t]{2}{*}{ Social Influence } & SI4 & $\begin{array}{l}\text { People around me who use mobile payment systems } \\
\text { have more prestige than those who do not }\end{array}$ & \multirow[t]{2}{*}{ Venkatesh et al. (2012) } \\
\hline & SI5 & $\begin{array}{l}\text { Using mobile payment systems is considered a status } \\
\text { symbol among my friends }\end{array}$ & \\
\hline \multirow[t]{4}{*}{$\begin{array}{l}\text { Facilitating } \\
\text { Conditions }\end{array}$} & FC1 & $\begin{array}{l}\text { I have the resources necessary to use mobile } \\
\text { payment systems }\end{array}$ & \multirow[t]{4}{*}{ Venkatesh et al. (2012) } \\
\hline & FC2 & $\begin{array}{l}\text { I have the knowledge necessary to use mobile } \\
\text { payment systems }\end{array}$ & \\
\hline & FC3 & $\begin{array}{l}\text { I can get help from others when I have difficulties } \\
\text { using mobile payment systems }\end{array}$ & \\
\hline & FC4 & $\begin{array}{l}\text { Specialized instructions concerning use of mobile } \\
\text { payment systems are available to me }\end{array}$ & \\
\hline \multirow[t]{3}{*}{$\begin{array}{l}\text { Behavioural } \\
\text { Intention }\end{array}$} & BI2 & $\begin{array}{l}\text { I will always try to use mobile payment systems in } \\
\text { my daily life }\end{array}$ & \multirow[t]{3}{*}{ Venkatesh et al. (2012) } \\
\hline & BI3 & I plan to use mobile payment systems frequently & \\
\hline & BI4 & $\begin{array}{l}\text { I will recommend others to use mobile payment } \\
\text { systems }\end{array}$ & \\
\hline \multirow{5}{*}{ Attitude } & AT2 & Using mobile payment systems is a wise idea & \multirow[t]{5}{*}{ Schierz et al. (2010) } \\
\hline & AT3 & I like the idea of using mobile systems & \\
\hline & AT4 & Using mobile payment systems is pleasant & \\
\hline & AT5 & Using mobile payment systems is beneficial & \\
\hline & AT6 & Using mobile payment systems is interesting & \\
\hline \multirow[t]{3}{*}{ Trust } & TR1 & I trust mobile payment systems to be reliable & \multirow{3}{*}{$\begin{array}{l}\text { Lu et al. (2011); } \\
\text { Srivastava et al. (2010) }\end{array}$} \\
\hline & TR2 & I trust mobile payment systems to be secure & \\
\hline & TR3 & I believe mobile payment systems to be trustworthy & \\
\hline \multirow[t]{4}{*}{ Anxiety } & ANX1 & I feel nervous about using mobile payment systems & \multirow[t]{4}{*}{ Rana et al. (2017) } \\
\hline & ANX2 & $\begin{array}{l}\text { It scares me to think that I can lose personal } \\
\text { information by wrongly using mobile payment } \\
\text { systems }\end{array}$ & \\
\hline & ANX3 & $\begin{array}{l}\text { I hesitate to use mobile payment systems in fear of } \\
\text { making mistakes I cannot correct }\end{array}$ & \\
\hline & ANX4 & $\begin{array}{l}\text { Using mobile payment systems is somewhat scary to } \\
\text { me }\end{array}$ & \\
\hline \multirow{4}{*}{$\begin{array}{l}\text { Perceived } \\
\text { Innovativeness }\end{array}$} & PIN1 & I like to experiment using mobile payment systems & \multirow{4}{*}{$\begin{array}{l}\text { Agarwal and Prasad } \\
\text { (1998) }\end{array}$} \\
\hline & PIN2 & $\begin{array}{l}\text { Among my peers, I am usually among the first to try } \\
\text { new ways of transaction mechanism through mobile } \\
\text { payment systems }\end{array}$ & \\
\hline & PIN3 & $\begin{array}{l}\text { If I heard about new transaction mechanism like } \\
\text { mobile payment systems, I look for ways to } \\
\text { experiment with it }\end{array}$ & \\
\hline & PIN4 & $\begin{array}{l}\text { In general, I am not hesitant to try out new mobile } \\
\text { payment systems }\end{array}$ & \\
\hline \multirow[t]{3}{*}{ Grievance } & GR1 & $\begin{array}{l}\text { There should be some authority to approach in the } \\
\text { case of failed mobile payment transactions }\end{array}$ & \multirow[t]{3}{*}{ Kumar et al. (2018) } \\
\hline & GR2 & $\begin{array}{l}\text { There should be transparency in settling claims for } \\
\text { failed mobile payment transactions }\end{array}$ & \\
\hline & GR3 & $\begin{array}{l}\text { Legal disputes about mobile payment should be } \\
\text { resolved in a timely manner }\end{array}$ & \\
\hline
\end{tabular}




\section{References}

Agarwal, R., \& Prasad, J. (1998). A conceptual and operational definition of personal innovativeness in the domain of information technology. Information systems research, 9(2), 204-215.

Agarwal, R., \& Prasad, J. (1999). Are individual differences germane to the acceptance of new information technologies? Decision sciences, 30(2), 361-391.

Ajzen, I. (1991). The theory of planned behavior. Organizational behavior and human decision processes, 50(2), 179-211.

Alaeddin, O., Rana, A., Zainudin, Z., \& Kamarudin, F. (2018). From physical to digital: Investigating consumer behaviour of switching to mobile wallet. Polish Journal of Management Studies, 17(2), 18-30.

Alalwan, A. A., Dwivedi, Y. K., \& Rana, N. P. (2017). Factors influencing adoption of mobile banking by Jordanian bank customers: Extending UTAUT2 with trust. International Journal of Information Management, 37(3), 99-110.

Alkhowaiter, W. A. (2020). Digital payment and banking adoption research in Gulf countries: A systematic literature review. International Journal of Information Management, 53, 102102.

Alshare, K., \& Mousa, A. (2014). The moderating effect of espoused cultural dimensions on consumer's intention to use mobile payment devices. In Proceedings of the 35th International Conference on Information Systems (pp.1-15).

Alshare, K. A., \& Lane, P. (2011). Predicting student-perceived learning outcomes and satisfaction in ERP courses: An empirical investigation. Communications of the Association for Information Systems: CAIS, 28, 34. DOI: 10.17705/1CAIS.02834

Anderson, J. C., \& Gerbing, D. W. (1988). Structural equation modeling in practice: A review and recommended two-step approach. Psychological bulletin, 103(3), 411-423.

Andreev, P., Pliskin, N., \& Rafaeli, S. (2012). Drivers and inhibitors of mobile-payment adoption by smartphone users. International Journal of E-Business Research (IJEBR), 8(3), 50-67.

Aroean, L., \& Michaelidou, N. (2014). Are innovative consumers emotional and prestigiously sensitive to price? Journal of Marketing Management, 30(3-4), 245-267.

Aslam, W., Ham, M., \& Arif, I. (2017). Consumer behavioral intentions towards mobile payment services: an empirical analysis in pakistan. Market-Tržište, 29(2), 161-176.

Augsburg, C., \& Hedman, J. (2014). Value added services and adoption of mobile payments. In Proceedings of the Sixteenth International Conference on Electronic Commerce (pp. 27-32).

Baabdullah, A. M., Alalwan, A. A., Rana, N. P., Kizgin, H., \& Patil, P. (2019). Consumer use of mobile banking (M-Banking) in Saudi Arabia: Towards an integrated model. International Journal of Information Management, 44, 38-52.

Bailey, A. A., Pentina, I., Mishra, A. S., \& Ben Mimoun, M. S. (2017). Mobile payments adoption by US consumers: an extended TAM. International Journal of Retail \& Distribution Management, 45(6), 626-640.

Baishya, K., \& Samalia, H. V. (2020). Extending unified theory of acceptance and use of technology with perceived monetary value for smartphone adoption at the bottom of the pyramid. International Journal of Information Management, 51, 102036.

Baptista, G., \& Oliveira, T. (2015). Understanding mobile banking: The unified theory of acceptance and use of technology combined with cultural moderators. Computers in Human Behavior, 50, 418-430.

Bhattacherjee, A. (2012). Social science research: Principles, methods, and practices.

Blunch, N. (2012). Introduction to structural equation modeling using IBM SPSS statistics and AMOS: Sage. 
Capgemini. (2019). World payments report, 2019. Retrieved from https://www.capgemini.com/es-es/wp-content/uploads/sites/16/2019/09/WorldPayments-Report-WPR-2019.pdf

Celik, H. (2016). Customer online shopping anxiety within the Unified Theory of Acceptance and Use Technology (UTAUT) framework. Asia Pacific Journal of Marketing and Logistics, 28(2), 278-307.

Cellan-Jones, R. (2012). Mobile money-has its moment come. BBC News: Technology, 16.

Chakravorti, B., (2017). Early Lessons from India's Demonetization Experiment, Harvard Business Review, 14.

Chandrasekhar, U., \& Nandagopal, R. (2016). Mobile payment usage intent in an Indian context: an exploratory study. Asian Journal of Information Technology, 15(3), 542552.

Chen, L.-d., \& Nath, R. (2008). Determinants of mobile payments: an empirical analysis. Journal of International Technology and Information Management, 17(1), 9-20.

Cheng, Y.-H., \& Huang, T.-Y. (2013). High speed rail passengers’ mobile ticketing adoption. Transportation Research Part C: Emerging Technologies, 30, 143-160.

Chin, W. W., \& Todd, P. A. (1995). On the use, usefulness, and ease of use of structural equation modeling in MIS research: a note of caution. MIS Quarterly, 19(2), 237-246.

Chong, A. Y.-L. (2013). A two-staged SEM-neural network approach for understanding and predicting the determinants of m-commerce adoption. Expert Systems with Applications, 40(4), 1240-1247.

Chhonker, M. S., Verma, D., \& Kar, A. K. (2017). Review of technology adoption frameworks in mobile commerce. Procedia computer science, 122, 888-895.

Chhonker, M. S., D. Verma, A. K. Kar, and P. Grover. (2018). M-commerce technology adoption: Thematic and citation analysis of scholarly research during (2008-2017). The Bottom Line, 31 (3/4), 208-33. doi:10.1108/BL-04-2018-0020.

Cowart, K. O., Fox, G. L., \& Wilson, A. E. (2008). A structural look at consumer innovativeness and self-congruence in new product purchases. Psychology \& marketing, 25(12), 1111-1130.

Crowe, M., Rysman, M., \& Stavins, J. (2010). Mobile payments at the retail point of sale in the United States: prospects for adoption. Review of Network Economics, 9(4), 2.

Czaja, S. J., Charness, N., Fisk, A. D., Hertzog, C., Nair, S. N., Rogers, W. A., \& Sharit, J. (2006). Factors predicting the use of technology: findings from the Center for Research and Education on Aging and Technology Enhancement (CREATE). Psychology and aging, 21(2), 333-352.

Daştan, I.., \& Gürler, C. (2016). Factors affecting the adoption of mobile payment systems: An empirical analysis. EMAJ: Emerging Markets Journal, 6(1), 17-24.

Davis, F. D. (1989). Perceived usefulness, perceived ease of use, and user acceptance of information technology. MIS Quarterly, 13(3), 319-340.

Davis, F. D., Bagozzi, R. P., \& Warshaw, P. R. (1989). User acceptance of computer technology: a comparison of two theoretical models. Management science, 35(8), 9821003.

De Kerviler, G., Demoulin, N. T., \& Zidda, P. (2016). Adoption of in-store mobile payment: Are perceived risk and convenience the only drivers? Journal of Retailing and Consumer Services, 31, 334-344.

De Luna, I. R., Liébana-Cabanillas, F., Sánchez-Fernández, J., \& Muñoz-Leiva, F. (2019). Mobile payment is not all the same: The adoption of mobile payment systems depending on the technology applied. Technological Forecasting and Social Change, 146, 931-944. 
Di Pietro, L., Mugion, R. G., Mattia, G., Renzi, M., \& Toni, M. (2015). The integrated model on mobile payment acceptance (IMMPA): An empirical application to public transport. Transportation Research Part C: Emerging Technologies, 56, 463-479.

Dwivedi, Y. K., Rana, N. P., Tamilmani, K., \& Raman, R. (2020). A Meta-Analysis Based Modified Unified Theory of Acceptance and Use of Technology (Meta-UTAUT): A Review of Emerging Literature. Current Opinion in Psychology, 36, 13-18.

Dwivedi, Y. K., Rana, N. P., Jeyaraj, A., Clement, M., \& Williams, M. D. (2019). Reexamining the unified theory of acceptance and use of technology (UTAUT): Towards a revised theoretical model. Information Systems Frontiers, 21(3), 719-734.

Dwivedi, Y., Rana, N., Chen, H., \& Williams, M. (2011). A Meta-analysis of the Unified Theory of Acceptance and Use of Technology (UTAUT). In Proceedings of IFIP international working conference on governance and sustainability in information systems-managing the transfer and diffusion of it (pp. 155-170). Springer, Berlin, Heidelberg.

Dwivedi, Y. K., \& Williams, M. D. (2008). Demographic influence on UK citizens'egovernment adoption. Electronic Government, an International Journal, 5(3), 261-274.

Dwivedi, Y. K., Khan, N., \& Papazafeiropoulou, A. (2007). Consumer adoption and usage of broadband in Bangladesh. Electronic Government, an International Journal, 4(3), 299313.

Escobar-Rodrguez, T., Carvajal-Trujillo, E., \& Monge-Lozano, P. (2014). Factors that influence the perceived advantages and relevance of Facebook as a learning tool: An extension of the UTAUT. Australasian Journal of Educational Technology, 30(2), 136151.

Evans, J. R., \& Mathur, A. (2005). The value of online surveys. Internet Research, 15(2), 195219.

Eze, U. C., Gan, G. G. G., Ademu, J., \& Tella, S. A. (2008). Modelling user trust and mobile payment adoption: a conceptual Framework. Communications of the IBIMA, 3(29), 224-231.

Fishbein, M., \& Ajzen, I. (1975). Belief, attitude, intention and behavior: An introduction to theory and research. Reading, MA: Addison-Wesley.

Fornell, C., \& Larcker, D. F. (1981). Evaluating structural equation models with unobservable variables and measurement error. Journal of Marketing Research, 18(1), 39-50.

Garrett, J. L., Rodermund, R., Anderson, N., Berkowitz, S., \& Robb, C. A. (2014). Adoption of mobile payment technology by consumers. Family and Consumer Sciences Research Journal, 42(4), 358-368.

Gefen, D., Straub, D., \& Boudreau, M.-C. (2000). Structural equation modeling and regression: Guidelines for research practice. Communications of the Association for Information systems, 4(1), 7. https://doi.org/10.17705/1CAIS.00407

Giovannini, C. J., Ferreira, J. B., Silva, J. F. d., \& Ferreira, D. B. (2015). The effects of trust transference, mobile attributes and enjoyment on mobile trust. BAR-Brazilian Administration Review, 12(1), 88-108.

Gsmaintelligence. (2017). Global Mobile Trends 2017. Retrieved from https://www.gsmaintelligence.com/research/?file=3df1b7d57b1e63a0cbc3d585feb82dc2\& download

Guo, K., \& Lu, S. (2017). An Empirical Examination of Initial Use Intention of Mobile Payment. Technical Bulletin, 55(10), 278-284.

Gupta, K. P., Manrai, R., \& Goel, U. (2019). Factors influencing adoption of payments banks by Indian customers: Extending UTAUT with perceived credibility. Journal of Asia Business Studies, 13(2), 173-195. 
Hair, J., Anderson, R., Tatham, R., \& Black, W. (2010). Multivariate Data Analysis: A Global Perspective, 7Pearson. Upper Saddle River, NJ.

Hair, J., Anderson, R. E., Tatham, R. L., \& Black, W. C. (1992). Multivariate data analysis with readings Macmillan Publishing Company. New York.

Hair, J. F., Black, W. C., Babin, B. J., Anderson, R. E., \& Tatham, R. L. (2006). Multivariate data analysis 6th Edition. Pearson Prentice Hall. New Jersey. humans: Critique and reformulation. Journal of Abnormal Psychology, 87, 49-74.

Hirschman, E. C. (1980). Innovativeness, novelty seeking, and consumer creativity. Journal of consumer research, 7(3), 283-295.

Ho, H., Fong, S., \& Yan, Z. (2008). User acceptance testing of mobile payment in various scenarios. In Proceedings of International Conference on e-Business Engineering (pp. 341-348). IEEE.

Hongxia, P., Xianhao, X., \& Weidan, L. (2011). Drivers and barriers in the acceptance of mobile payment in China. In Proceedings of International Conference on E-business and E-government (ICEE) (pp. 1-4). IEEE.

Howard, G. S., \& Smith, R. D. (1986). Computer anxiety in management: Myth or reality? Communications of the ACM, 29(7), 611-615.

Hu, L. t., \& Bentler, P. M. (1999). Cutoff criteria for fit indexes in covariance structure analysis: Conventional criteria versus new alternatives. Structural equation modeling: a multidisciplinary journal, 6(1), 1-55.

Huang, Y., \& Liu, W. (2012). The impact of privacy concern on users' usage intention of mobile payment. In Proceedings of International Conference on Information Management, Innovation Management and Industrial Engineering (Vol. 3, pp. 90-93). IEEE.

Iacobucci, D. (2009). Everything you always wanted to know about SEM (structural equations modeling) but were afraid to ask. Journal of Consumer Psychology, 19(4), 673-680.

Igbaria, M. (1990). End-user computing effectiveness: A structural equation model. Omega, 18(6), 637-652.

Kats, R. (2018). The Mobile Payments Series: India. Retrieved from https://www.emarketer.com/content/the-mobile-payments-series-india

Kapoor, K. K., Dwivedi, Y. K., \& Williams, M. D. (2014). Innovation adoption attributes: a review and synthesis of research findings. European Journal of Innovation Management, 17(3), 327-348.

Karjaluoto, H., Shaikh, A. A., Saarijärvi, H., \& Saraniemi, S. (2019). How perceived value drives the use of mobile financial services apps. International Journal of Information Management, 47, 252-261.

Kim, C., Mirusmonov, M., \& Lee, I. (2010). An empirical examination of factors influencing the intention to use mobile payment. Computers in Human Behavior, 26(3), 310-322.

Kim, Y., Park, Y.-J., Choi, J., \& Yeon, J. (2016). The adoption of mobile payment services for "Fintech". International Journal of Applied Engineering Research, 11(2), 1058-1061.

Koenig-Lewis, N., Marquet, M., Palmer, A., \& Zhao, A. L. (2015). Enjoyment and social influence: predicting mobile payment adoption. The Service Industries Journal, 35(10), 537-554.

Korobili, S., Togia, A., \& Malliari, A. (2010). Computer anxiety and attitudes among undergraduate students in Greece. Computers in Human Behavior, 26(3), 399-405.

Kumar, A., Adlakaha, A., \& Mukherjee, K. (2018). The effect of perceived security and grievance redressal on continuance intention to use M-wallets in a developing country. International Journal of Bank Marketing, 36(7), 1170-1189. 
Liébana-Cabanillas, F., Sánchez-Fernández, J., \& Muñoz-Leiva, F. (2014a). Antecedents of the adoption of the new mobile payment systems: The moderating effect of age. Computers in Human Behavior, 35, 464-478.

Liébana-Cabanillas, F., Sánchez-Fernández, J., \& Muñoz-Leiva, F. (2014b). The moderating effect of experience in the adoption of mobile payment tools in Virtual Social Networks: The m-Payment Acceptance Model in Virtual Social Networks (MPAMVSN). International Journal of Information Management, 34(2), 151-166.

Liu, B. (2012). Understanding Consumers' Intention to Use Mobile Payment Services: The Perspective of University Students in Northern Jiangsu Area. In Proceedings of Second International Conference on Business Computing and Global Informatization (pp. 257260). IEEE.

Lu, Y., Yang, S., Chau, P. Y., \& Cao, Y. (2011). Dynamics between the trust transfer process and intention to use mobile payment services: A cross-environment perspective. Information \& management, 48(8), 393-403.

Makki, A. M., Ozturk, A. B., \& Singh, D. (2016). Role of risk, self-efficacy, and innovativeness on behavioral intentions for mobile payment systems in the restaurant industry. Journal of Foodservice Business Research, 19(5), 454-473.

Malhotra, N. K., Kim, S. S., \& Patil, A. (2006). Common method variance in IS research: A comparison of alternative approaches and a reanalysis of past research. Management science, 52(12), 1865-1883.

Mallat, N. (2007). Exploring consumer adoption of mobile payments-A qualitative study. The Journal of Strategic Information Systems, 16(4), 413-432.

Martin, J. (2016). 7 reasons mobile payments still aren't mainstream. Retrieved from https://www.cio.com/article/3080045/7-reasons-mobile-payments-still-arentmainstream.html

McKnight, D. H., \& Chervany, N. L. (2001). What trust means in e-commerce customer relationships: An interdisciplinary conceptual typology. International journal of electronic commerce, 6(2), 35-59.

McKnight, D. H., Choudhury, V., \& Kacmar, C. (2002). Developing and validating trust measures for e-commerce: An integrative typology. Information systems research, 13(3), 334-359.

McMaster, T., \& Wastell, D. (2005). Diffusion-or delusion? Challenging an IS research tradition. Information Technology \& People, 18(4), 383-404.

Morosan, C., \& DeFranco, A. (2016). It's about time: Revisiting UTAUT2 to examine consumers' intentions to use NFC mobile payments in hotels. International Journal of Hospitality Management, 53, 17-29.

Musa, A., Khan, H. U., \& AlShare, K. A. (2015). Factors influence consumers' adoption of mobile payment devices in Qatar. International Journal of Mobile Communications, 13(6), 670-689.

NPCI (n.d). About NPCI. Retrieved from https://www.npci.org.in/about-us-background

Nunnally, J. (1978). Psychometric methods. In: New York: McGraw-Hill.

Oliveira, T., Thomas, M., Baptista, G., \& Campos, F. (2016). Mobile payment: Understanding the determinants of customer adoption and intention to recommend the technology. Computers in Human Behavior, 61, 404-414.

Patil, P. P., Dwivedi, Y. K., \& Rana, N. P. (2017). Digital payments adoption: an analysis of literature. In Proceedings of Conference on e-Business, e-Services and e-Society (pp. 61-70). Springer, Cham.

Phonthanukitithaworn, C., Sellitto, C., \& Fong, M. W. L. (2015). User intentions to adopt mobile payment services: A study of early adopters in Thailand. Journal of Internet Banking and Commerce, 20(1), 1-29. 
Podsakoff, P. M., MacKenzie, S. B., Lee, J.-Y., \& Podsakoff, N. P. (2003). Common method biases in behavioral research: A critical review of the literature and recommended remedies. Journal of Applied Psychology, 88(5), 879-903.

PWC. (2018). Propelling India towards global leadership in e-commerce. Retrieved from https://www.pwc.in/research-insights/2018/propelling-india-towards-global-leadership-ine-commerce.html

Qasim, H., \& Abu-Shanab, E. (2016). Drivers of mobile payment acceptance: The impact of network externalities. Information Systems Frontiers, 18(5), 1021-1034.

Rana, N. P., Dwivedi, Y. K., Lal, B., Williams, M. D., \& Clement, M. (2017). Citizens' adoption of an electronic government system: towards a unified view. Information Systems Frontiers, 19(3), 549-568.

Rana, N. P., Dwivedi, Y. K., Williams, M. D., \& Weerakkody, V. (2016). Adoption of online public grievance redressal system in India: Toward developing a unified view. Computers in Human Behavior, 59, 265-282.

Rana, N. P., Dwivedi, Y. K., \& Williams, M. D. (2013). Evaluating alternative theoretical models for examining citizen centric adoption of e-government. Transforming Government: People, Process and Policy, 7(1), 27-49.

Salahshour Rad, M., Nilashi, M., Mohamed Dahlan, H., \& Ibrahim, O. (2019). Academic researchers' behavioural intention to use academic social networking sites: A case of Malaysian research universities. Information Development, 35(2), 245-261.

San-Martín, S., López-Catalán, B., \& Ramón-Jerónimo, M. A. (2013). Mobile shoppers: types, drivers, and impediments. Journal of Organizational Computing and Electronic Commerce, 23(4), 350-371.

Saunders, M., Lewis, P., \& Thornhill, A. (2007). Research methods. Business Students. Financial Times/Prentice Hall.

Schierz, P. G., Schilke, O., \& Wirtz, B. W. (2010). Understanding consumer acceptance of mobile payment services: An empirical analysis. Electronic Commerce Research and Applications, 9(3), 209-216.

Shaikh, A. A., Glavee-Geo, R., \& Karjaluoto, H. (2018). How relevant are risk perceptions, effort, and performance expectancy in mobile banking adoption? International Journal of E-Business Research (IJEBR), 14(2), 39-60.

Shankar, A., \& Datta, B. (2018). Factors affecting mobile payment adoption intention: An Indian perspective. Global Business Review, 19(3), 72-89.

Sharma, S. K., \& Sharma, M. (2019). Examining the role of trust and quality dimensions in the actual usage of mobile banking services: an empirical investigation. International Journal of Information Management, 44, 65-75.

Shaw, N. (2014). The mediating influence of trust in the adoption of the mobile wallet. Journal of Retailing and Consumer Services, 21(4), 449-459.

Shin, D.-H. (2010). Modeling the interaction of users and mobile payment system: Conceptual framework. International Journal of Human-Computer Interaction, 26(10), 917-940.

Shin, S., \& Lee, W.-j. (2014). The effects of technology readiness and technology acceptance on NFC mobile payment services in Korea. Journal of Applied Business Research, 30(6), 1615-1626.

Simonson, M. R., Maurer, M., Montag-Torardi, M., \& Whitaker, M. (1987). Development of a standardized test of computer literacy and a computer anxiety index. Journal of educational computing research, 3(2), 231-247.

Singh, B. P., Grover, P., \& Kar, A. K. (2017). Quality in mobile payment service in India. In Proceedings of Conference on e-Business, e-Services and e-Society (pp. 183-193). Springer, Cham. 
Singh, N., Sinha, N., \& Liébana-Cabanillas, F. J. (2020). Determining factors in the adoption and recommendation of mobile wallet services in India: Analysis of the effect of innovativeness, stress to use and social influence. International Journal of Information Management, 50, 191-205.

Sivathanu, B. (2019). Adoption of digital payment systems in the era of demonetization in India: An empirical study. Journal of Science and Technology Policy Management, 10(1), 143-171.

Slade, E., Williams, M., Dwivedi, Y., \& Piercy, N. (2015a). Exploring consumer adoption of proximity mobile payments. Journal of Strategic Marketing, 23(3), 209-223.

Slade, E. L., Dwivedi, Y. K., Piercy, N. C., \& Williams, M. D. (2015b). Modeling consumers' adoption intentions of remote mobile payments in the United Kingdom: extending UTAUT with innovativeness, risk, and trust. Psychology \& marketing, 32(8), 860-873.

Slade, E. L., Williams, M. D., \& Dwivedi, Y. K. (2014). Devising a research model to examine adoption of mobile payments: An extension of UTAUT2. The marketing review, 14(3), 310-335.

Srivastava, S. C., Chandra, S., \& Theng, Y.-L. (2010). Evaluating the role of trust in consumer adoption of mobile payment systems: An empirical analysis. Communications of the Association for Information systems, 27(1), 561-588.

Statistica. (2018). Number of apps available in leading app stores as of 3rd quarter 2018. Retrieved from https://www.statista.com/statistics/276623/number-of-apps-availablein-leading-app-stores/

Stefi, A. (2015). Do Developers Make Unbiased Decisions?-The Effect of Mindfulness and Not-Invented-Here Bias on the Adoption of Software Components. In, Proceedings of Twenty-Third European Conference on Information Systems (ECIS), Münster, Germany.

Šumak, B., Polancic, G., \& Hericko, M. (2010). An empirical study of virtual learning environment adoption using UTAUT. In Proceedings of Second international conference on mobile, hybrid, and on-line learning (pp. 17-22). IEEE.

Tabachnick, B. G., \& Fidell, L. S. (2007). Using multivariate statistics: Allyn \& Bacon/Pearson Education.

Tamilmani, K., Rana, N. P., \& Dwivedi, Y. K. (2017). A systematic review of citations of UTAUT2 article and its usage trends. In Proceedings of Conference on e-Business, eServices and e-Society (pp. 38-49). Springer, Cham.

Tamilmani, K., Rana, N. P., Dwivedi, Y. K., Sahu, G. P., \& Roderick, S. (2018a). Exploring the Role of 'Price Value' for Understanding Consumer Adoption of Technology: A Review and Meta-analysis of UTAUT2 based Empirical Studies. In Proceedings of Twenty-Second Pacific Asia Conference on Information Systems, Japan.

Tamilmani, K., Rana, N. P., Alryalat, M. A. A., Al-Khowaiter, W. A., \& Dwivedi, Y. K. (2018b). Social media research in the context of emerging markets: An analysis of extant literature from information systems perspective. Journal of Advances in Management Research, 15(2), 115-129.

Tamilmani, K., Rana, N. P., \& Dwivedi, Y. K. (2020). Consumer Acceptance and Use of Information Technology: A Meta-Analytic Evaluation of UTAUT2. Information Systems Frontiers, 1-19. https://doi.org/10.1007/s10796-020-10007-6

Tan, G. W.-H., Ooi, K.-B., Chong, S.-C., \& Hew, T.-S. (2014). NFC mobile credit card: the next frontier of mobile payment? Telematics and Informatics, 31(2), 292-307.

Taylor, S., \& Todd, P. A. (1995). Understanding information technology usage: A test of competing models. Information systems research, 6(2), 144-176. 
Thakur, R., \& Srivastava, M. (2014). Adoption readiness, personal innovativeness, perceived risk and usage intention across customer groups for mobile payment services in India. Internet Research, 24(3), 369-392.

Tian, Y., \& Dong, H. (2013). An analysis of key factors affecting user acceptance of mobile payment. In Proceedings of Second International Conference on Informatics \& Applications (ICIA) (pp. 240-246). IEEE.

Venkatesh, V., \& Bala, H. (2008). Technology acceptance model 3 and a research agenda on interventions. Decision sciences, 39(2), 273-315.

Venkatesh, V., \& Davis, F. D. (2000). A theoretical extension of the technology acceptance model: Four longitudinal field studies. Management science, 46(2), 186-204.

Venkatesh, V., Morris, M. G., Davis, G. B., \& Davis, F. D. (2003). User acceptance of information technology: Toward a unified view. MIS Quarterly, 27(3), 425-478.

Venkatesh, V., Thong, J. Y., \& Xu, X. (2012). Consumer acceptance and use of information technology: extending the unified theory of acceptance and use of technology. MIS Quarterly, 36(1), 157-178.

Waseem, D., Biggemann, S., \& Garry, T. (2018). Value co-creation: The role of actor competence. Industrial Marketing Management, 70, 5-12.

Weerakkody, V., Dwivedi, Y., Williams, M., Brooks, L., \& Mwange, A. (2007). E-government implementation in Zambia: contributing factors. In Proceedings of 13th Americas Conference on Information Systems (AMCIS), Keystone, Colorado.

Weerakkody, V., Dwivedi, Y. K., \& Kurunananda, A. (2009). Implementing e-government in Sri Lanka: Lessons from the UK. Information Technology for Development, 15(3), 171-192.

Weerakkody, V., Irani, Z., Kapoor, K., Sivarajah, U., \& Dwivedi, Y. K. (2017). Open data and its usability: an empirical view from the Citizen's perspective. Information Systems Frontiers, 19(2), 285-300.

Whetten, D. A. (1989). What constitutes a theoretical contribution? Academy of management review, 14(4), 490-495.

Whetten, D. A. (2009). An examination of the interface between context and theory applied to the study of Chinese organizations. Management and Organization Review, 5(1), 2956.

Williams, M. D., Rana, N. P., \& Dwivedi, Y. K. (2015). The unified theory of acceptance and use of technology (UTAUT): A literature review. Journal of enterprise information management, 28(3), 443-488.

Wu, J., \& Du, H. (2012). Toward a better understanding of behavioral intention and system usage constructs. European Journal of Information Systems, 21(6), 680-698.

Wu, J., Liu, L., \& Huang, L. (2016). Exploring User Acceptance of Innovative Mobile Payment Service in Emerging Market: the Moderating effect of diffusion stages of WeChat Payment in China. In 20th Pacific Asia Conference on Information Systems, Taiwan.

Wu, J., Liu, L., \& Huang, L. (2017). Consumer acceptance of mobile payment across time: Antecedents and moderating role of diffusion stages. Industrial Management \& Data Systems, 117(8), 1761-1776.

Wulandari, N. (2017). Cashless Payment in Tourism. An Application of Technology Acceptance Model. Journal of Environmental Management \& Tourism, 8(8 (24)), 1550-1553.

Yang, K. (2012). Consumer technology traits in determining mobile shopping adoption: An application of the extended theory of planned behavior. Journal of Retailing and Consumer Services, 19(5), 484-491. 
Yang, K., \& Forney, J. C. (2013). The moderating role of consumer technology anxiety in mobile shopping adoption: differential effects of facilitating conditions and social influences. Journal of Electronic Commerce Research, 14(4), 334-347.

Yang, S., Lu, Y., Gupta, S., Cao, Y., \& Zhang, R. (2012). Mobile payment services adoption across time: An empirical study of the effects of behavioral beliefs, social influences, and personal traits. Computers in Human Behavior, 28(1), 129-142.

Yang, Q., Gong, X., Zhang, K. Z., Liu, H., \& Lee, M. K. (2020). Self-disclosure in mobile payment applications: Common and differential effects of personal and proxy control enhancing mechanisms. International Journal of Information Management, 102065.

Zhanga, A., Yue, X., \& Kong, Y. (2011). Exploring culture factors affecting the adoption of mobile payment. In Proceedings of 10th International Conference on Mobile Business (pp. 263-267). IEEE.

Zhong, J., Dhir, A., Nieminen, M., Hämäläinen, M., \& Laine, J. (2013). Exploring consumer adoption of mobile payments in China. In Proceedings of International Conference on Making Sense of Converging Media (pp. 318-325).

Zhou, T. (2012). Examining mobile banking user adoption from the perspectives of trust and flow experience. Information Technology and Management, 13(1), 27-37.

Zhou, T. (2013). An empirical examination of continuance intention of mobile payment services. Decision Support Systems, 54(2), 1085-1091.

Zhou, T. (2014a). An empirical examination of initial trust in mobile payment. Wireless personal communications, 77(2), 1519-1531.

Zhou, T. (2014b). Understanding the determinants of mobile payment continuance usage. Industrial Management \& Data Systems, 114(6), 936-948.

Zhou, T., Lu, Y., \& Wang, B. (2010). Integrating TTF and UTAUT to explain mobile banking user adoption. Computers in Human Behavior, 26(4), 760-767. 